\title{
Lung and Pleura
}

\author{
Mark C. Liszewski, Pierluigi Ciet, and Edward Y. Lee
}

\section{Introduction}

Disorders of the lungs and pleura are common in children and are a frequent indication for medical imaging. Over the past decade, a combination of advances in magnetic resonance (MR) imaging scanner technology and increased concern about the effects of ionizing radiation has led to increased utilization of MR imaging in the pediatric population. Despite this general trend, there has been slower adoption of MR imaging to evaluate the lungs and pleura due to technical limitations including motion artifact, low signal-tonoise ratios, and signal dephasing at air-tissue interfaces. As MR imaging technology advances, many of these technical hurdles are being overcome, and MR imaging of the lungs and pleura has begun to be a feasible option for evaluation of many pediatric pleuropulmonary conditions. Therefore, an up-to-date understanding of these emerging applications is important to practitioners performing MR imaging in infants and children.

In this chapter, an overview of MR imaging techniques to evaluate the lungs and pleura in children is discussed. Normal anatomy and development of the lungs and pleura are described, and the MR imaging findings in a spectrum of pediatric lung and pleural disease are illustrated.

M. C. Liszewski ( $\square)$

Division of Pediatric Radiology, Departments of Radiology and Pediatrics, The Children's Hospital at Montefiore and Montefiore Medical Center, Bronx, NY, USA

P. Ciet

Department of Radiology and Nuclear Medicine, Department of Pediatric Pulmonology, Sophia Children's Hospital Erasmus Medical Center, Rotterdam, The Netherlands

E. Y. Lee

Division of Thoracic Imaging, Department of Radiology, Boston Children's Hospital, Harvard Medical School, Boston, MA, USA

\section{Magnetic Resonance Imaging Techniques}

A main advantage of MR imaging is the ability to obtain cross-sectional images with high-contrast resolution without requiring ionizing radiation. Because of technical challenges when imaging the lungs and pleura, the key to successful MR imaging of the thorax lies in appropriate patient preparation and use of optimized pulse sequences and protocols.

\section{Patient Preparation}

MR imaging is an imaging modality that is highly sensitive to motion artifact, and successful MR imaging of the chest depends on appropriate patient selection and preparation prior to imaging. Selection of a successful technique largely depends on the age of the child and the assessment of the child's ability to follow instructions.

Infants are often able to undergo successful MR imaging utilizing a "feed and wrap" technique, in which the child is fed and swaddled prior to MR imaging [1]. After infancy, nearly all children under 5 years of age are not able to hold still or adequately follow breathing instructions and therefore require moderate sedation or general anesthesia for successful MR imaging. Examinations performed under moderate sedation must utilize sequences that are optimized for quite free breathing. Examinations performed under general anesthesia may utilize sequences that require apnea. Children as young as 5 years of age may be candidates for MR imaging without sedation or anesthesia but must be carefully assessed prior to imaging to gauge their ability to cooperate for the examination. In order for an examination to be successful, preparation and coaching are essential prior to the MR imaging. Children must practice breathing maneuvers and become familiar with the scanner prior to the examination, ideally in a mock scanner environment with the assistance of child life specialists. During practice sessions, children learn to hold their breaths at end-inspiration and end-expiration, rapidly breathe in and out, and perform coughing maneuvers. 


\section{MR Imaging Pulse Sequences and Protocols}

Historically, MR imaging of the lungs and pleura has been hampered by technical factors inherent to these organ systems including respiratory motion artifact, low signal-to-noise ratios, and signal dephasing at air-tissue interphases. However, in recent years, technological advances have helped to overcome many of these impediments, and diagnostic MR imaging of the lungs and pleura can now be achieved on MR imaging scanners currently in use at many medical centers. MR imaging protocols of the lungs and pleura mainly consist of spin-echo and gradient-echo sequences which can often produce image qual- ity that approaches that of CT [2]. Newer techniques including ultra-short (UTE) or zero echo time (ZTE) sequences provide even better image quality which is on par with CT $[3,4]$. When pediatric patients are unable to cooperate with breathing instructions, respiratory gating can be employed by utilizing a pneumobelt or navigator echo sequence [2]. Specialized sequences, which minimize motion artifact, can be used to obtain images during free breathing, including helicoidal (PROPELLER@GE) or radial (STARVIBE@SIEMENS) $\mathrm{k}$-space acquisition schemes [5, 6]. MR imaging also has the ability to provide information about ventilation, inflammation, perfusion, and structure, under the acronym VIPS [7-10].

Table 1.1 MR imaging sequences for ventilation, inflammation, perfusion, and structural (VIPS) MR imaging of the lung and pleura

\begin{tabular}{|c|c|c|c|c|c|c|}
\hline SEQUENCE & ACRONYMS & $\begin{array}{l}\text { MR } \\
\text { IMAGING } \\
\text { SYSTEM }\end{array}$ & $\begin{array}{l}\text { AVERAGE } \\
\text { ACQUISITION } \\
\text { TIME (FOR THE } \\
\text { ENTIRE CHEST } \\
\text { COVERAGE) }\end{array}$ & $\begin{array}{l}\text { SPATIAL } \\
\text { RESOLUTION }\end{array}$ & $\begin{array}{l}\text { TEMPORAL } \\
\text { RESOLUTION }\end{array}$ & $\begin{array}{l}\text { SCAN } \\
\text { PARAMETERS }\end{array}$ \\
\hline \multicolumn{7}{|l|}{ Ventilation } \\
\hline 2D gradient echo & $\begin{array}{l}\text { SSFP (GE) } \\
\text { TruFISP } \\
\text { (SIEMENS) } \\
\text { bFFE (PHILIPS) }\end{array}$ & $1.5 \mathrm{~T}$ & $3-9 \min$ & $\begin{array}{l}\mathrm{FOV}=450 \times 450 \mathrm{~mm} \\
\mathrm{SL}=12 \mathrm{~mm} \\
\text { Matrix }=128 \times 128\end{array}$ & $\begin{array}{l}3.33 \text { images/s } \\
\text { acquisition }\end{array}$ & $\begin{array}{l}\text { TE/TR } \\
0.67 \mathrm{~ms} / 1.46 \mathrm{~ms} \\
\mathrm{FA}=65^{\circ} \\
\mathrm{BW}=2056 \mathrm{~Hz} / \text { pixel }\end{array}$ \\
\hline 2D gradient echo & $\begin{array}{l}\text { 2D SPGR }(\mathrm{GE}) \\
\text { 2D FLASH } \\
\text { (SIEMENS) } \\
\text { 2D FFE }\end{array}$ & 1.5 and $3 \mathrm{~T}$ & $3-9 \min$ & $\begin{array}{l}\text { FOV }=500 \times 500 \mathrm{~mm} \\
\mathrm{SL}=15 \mathrm{~mm} \\
\text { Matrix }=256 \times 192\end{array}$ & $\begin{array}{l}3.08 \text { images/s } \\
\text { acquisition }\end{array}$ & $\begin{array}{l}\text { TE/TR } 1.04 \mathrm{~ms} / 3 \mathrm{~ms} \\
\mathrm{FA}=5^{\circ} \\
\mathrm{BW}=1500 \mathrm{~Hz} / \text { pixel }\end{array}$ \\
\hline \multicolumn{7}{|l|}{ Inflammation } \\
\hline $\begin{array}{l}\text { 2D single-shot } \\
\text { echo- planar } \\
\text { imaging } \\
\text { sequence (EPI) }\end{array}$ & $\begin{array}{l}\text { EPI-DWI } \\
\text { (SIEMENS/GE/ } \\
\text { PHILIPS) }\end{array}$ & $1.5 \mathrm{~T}$ & $5-7 \mathrm{~min}$ & $\begin{array}{l}\text { FOV } \\
\text { SL }=5 \mathrm{~mm} \\
\text { Matrix }\end{array}$ & Low & $\begin{array}{l}\text { TE/TR } \\
83 \mathrm{~ms} / 5632 \mathrm{~ms} \\
\mathrm{FA}=90^{\circ} \\
\mathrm{B}=0 \text { and } 600 \mathrm{~s} / \mathrm{mm}^{2}\end{array}$ \\
\hline $\begin{array}{l}\text { 2D single-shot } \\
\text { echo- planar } \\
\text { imaging } \\
\text { sequence (EPI) }\end{array}$ & EPI-DWI & $1.5 \mathrm{~T}$ & $5-7 \mathrm{~min}$ & $\begin{array}{l}\text { Voxel size } \\
2.5 \times 2.5 \times 6 \mathrm{~mm}^{3}\end{array}$ & Low & $\begin{array}{l}\text { TE/TR } \\
54 \mathrm{~ms} / 4800 \mathrm{~ms} \\
\mathrm{FA}=90^{\circ} \\
\mathrm{BW}=1644 \mathrm{~Hz} / \text { pixel } \\
\mathrm{B}=0,10,20,30,50, \\
70,100,150,200, \\
400,800 \mathrm{~s} / \mathrm{mm}^{2}\end{array}$ \\
\hline $\begin{array}{l}\text { 2D T2-weighted } \\
\text { Turbo spin echo }\end{array}$ & $\begin{array}{l}\text { TSE (SIEMENS) } \\
\text { FSE (GE) } \\
\text { TSE (PHILIPS) }\end{array}$ & $\begin{array}{l}1.5 \mathrm{~T} \text { and } \\
3 \mathrm{~T}\end{array}$ & $5-7 \mathrm{~min}$ & $\begin{array}{l}\text { FOV }=400 \mathrm{~mm} \\
\mathrm{SL}=5-7 \mathrm{~mm} \\
\text { Matrix }=256 \times 192\end{array}$ & Low & $\begin{array}{l}\text { TE/TR } \\
80 \mathrm{~ms} / 2000-4000 \mathrm{~ms} \\
\mathrm{FA}=90^{\circ} \\
\mathrm{BW}=1644 \mathrm{~Hz} / \text { pixel } \\
\text { Fat suppression } \\
\text { mode = SPAIR }\end{array}$ \\
\hline \multicolumn{7}{|c|}{ Perfusion/Angiography } \\
\hline 2D gradient echo & $\begin{array}{l}\text { SSFP (GE) } \\
\text { TruFISP } \\
\text { (SIEMENS) } \\
\text { bFFE (PHILIPS) }\end{array}$ & \multicolumn{5}{|c|}{ See scan parameters above } \\
\hline $2 \mathrm{D}$ gradient echo & $\begin{array}{l}\text { 2D SPGR }(\mathrm{GE}) \\
\text { 2D FLASH } \\
(\mathrm{SIEMENS}) \\
2 \mathrm{D} \mathrm{FFE}\end{array}$ & \multicolumn{5}{|c|}{ See scan parameters above } \\
\hline $\begin{array}{l}\text { 3D gradient echo } \\
\text { T1-weighted }\end{array}$ & $\begin{array}{l}\text { FLASH 3D } \\
\text { (SIEMENS) } \\
\text { SPGR (GE) } \\
\text { FFE (PHILIPS) }\end{array}$ & 1.5 and $3 \mathrm{~T}$ & $12-20 \mathrm{~s}$ & $\begin{array}{l}\mathrm{FOV}=460 \mathrm{~mm} \\
\text { matrix }=40 \times 192 \times 256 \\
(\text { isotropic voxel as low as } \\
\left(\mathrm{mm}^{3}\right)\end{array}$ & Low & $\begin{array}{l}\mathrm{TR}=2.5-3 \mathrm{~ms} \\
\mathrm{TE}=1.0-1.5 \mathrm{~ms} \\
\mathrm{FA}=30^{\circ}-40^{\circ}\end{array}$ \\
\hline $\begin{array}{l}\text { 3D gradient echo } \\
\text { T1-weighted }\end{array}$ & $\begin{array}{l}\text { Twist(SIEMENS) } \\
\text { TRICKS (GE) } \\
\text { TRACK (PHILIPS) }\end{array}$ & 1.5 and $3 \mathrm{~T}$ & $\begin{array}{l}\text { Breath-hold } \\
\text { (end-expiratory)/ } \\
\text { shallow breathing }\end{array}$ & $\begin{array}{l}\mathrm{FOV}=460 \mathrm{~mm} \\
\text { matrix }=32 \times 96 \times 128\end{array}$ & $\begin{array}{l}\text { High, } 0.5-1 \mathrm{~s} / \\
\text { volume }\end{array}$ & $\begin{array}{l}\mathrm{TR}=2.0-2.5 \mathrm{~ms} \\
\mathrm{TE}=0.8-1.0 \mathrm{~ms} \\
\mathrm{FA}=30^{\circ}-40^{\circ}\end{array}$ \\
\hline
\end{tabular}


Table 1.1 (continued)

\begin{tabular}{|c|c|c|c|c|c|c|}
\hline SEQUENCE & ACRONYMS & $\begin{array}{l}\text { MR } \\
\text { IMAGING } \\
\text { SYSTEM }\end{array}$ & $\begin{array}{l}\text { AVERAGE } \\
\text { ACQUISITION } \\
\text { TIME (FOR THE } \\
\text { ENTIRE CHEST } \\
\text { COVERAGE) }\end{array}$ & $\begin{array}{l}\text { SPATIAL } \\
\text { RESOLUTION }\end{array}$ & $\begin{array}{l}\text { TEMPORAL } \\
\text { RESOLUTION }\end{array}$ & $\begin{array}{l}\text { SCAN } \\
\text { PARAMETERS }\end{array}$ \\
\hline \multicolumn{7}{|l|}{ Structure } \\
\hline $2 \mathrm{D}$ & $\begin{array}{l}\text { T2-weighted } \\
\text { BLADE } \\
\text { (SIEMENS) } \\
\text { T2-weighted } \\
\text { PROPELLER (GE) } \\
\text { T2-weighted } \\
\text { MultiVane } \\
\text { (PHILIPS) } \\
\pm \text { FAT suppression }\end{array}$ & 1.5 and $3 \mathrm{~T}$ & $\begin{array}{l}\text { End-expiratory } \\
\text { with navigator } \\
\text { echo triggering } \\
3 \text { to } 7 \text { min } \\
\text { according } \\
\text { respiratory pace } \\
\text { and pattern }\end{array}$ & $\begin{array}{l}\text { FOV: } 380-400 \mathrm{~mm} \\
\text { Matrix }=200 \times 200 \\
\text { SL }=5-6 \mathrm{~mm} \text {, axial and } \\
\text { coronal }\end{array}$ & Low & $\begin{array}{l}\mathrm{TR}=1000-2000 \\
\mathrm{TE}=27-60 \mathrm{~ms} \\
\mathrm{FA}=90^{\circ}-150^{\circ}\end{array}$ \\
\hline $2 \mathrm{D}$ & $\begin{array}{l}\text { TRUFISP } \\
\text { (SIEMENS) } \\
\text { SSFP (GE) } \\
\text { Balanced FFE } \\
\text { (PHILIPS) }\end{array}$ & $1.5 \mathrm{~T}$ & $12-20 \mathrm{~s}$ & $\begin{array}{l}\text { FOV }=400 \mathrm{~mm} \\
\text { Matrix }=160 \times 160 \\
\text { SL } 2.5-5 \mathrm{~mm}\end{array}$ & High & $\begin{array}{l}\mathrm{TR}=1.08 \mathrm{~ms} \\
\mathrm{TE}=0.42 \mathrm{~ms} \\
\mathrm{FA}=20^{\circ} \\
\mathrm{BW}=1776 \mathrm{~Hz} / \text { pixel }\end{array}$ \\
\hline $3 \mathrm{D}$ & $\begin{array}{l}\text { SPACE (SIEMENS) } \\
\text { CUBE (GE) } \\
\text { VISTA (PHILIPS) }\end{array}$ & $1.5 \mathrm{~T}-3 \mathrm{~T}$ & $\begin{array}{l}\text { End-expiratory } \\
\text { with navigator } \\
\text { echo triggering } \\
5 \mathrm{~min}\end{array}$ & $\begin{array}{l}\mathrm{FOV}=320 \mathrm{~mm} \\
\text { Matrix }=160 \times 160 \\
\mathrm{SL}=2 \mathrm{~mm}\end{array}$ & Low & $\begin{array}{l}\mathrm{TR}=940 \mathrm{~ms} \\
\mathrm{TE}=60 \mathrm{~ms} \\
\mathrm{FA}=90^{\circ} \\
\mathrm{BW}=355 \mathrm{~Hz} / \text { pixel } \\
\text { Echo train } \\
\text { length }=120\end{array}$ \\
\hline $3 \mathrm{D}$ & $\begin{array}{l}\text { VIBE(SIEMENS) } \\
\text { SPGR (GE) } \\
\text { THRIVE } \\
\text { (PHILIPS) }\end{array}$ & $1.5 \mathrm{~T}-3 \mathrm{~T}$ & $\begin{array}{l}\text { Breath-hold } \\
10-12 \mathrm{~s} \\
\text { (inspiratory and } \\
\text { expiratory) }\end{array}$ & $\begin{array}{l}\mathrm{FOV}=400 \mathrm{~mm} \\
\text { Matrix }=200 \times 200 \\
\mathrm{SL}=2 \mathrm{~mm}\end{array}$ & High & $\begin{array}{l}\mathrm{TR}=1.7 \mathrm{~ms} \\
\mathrm{TE}=0.7 \mathrm{~ms} \\
\mathrm{FA}=2^{\circ} \\
\mathrm{BW}=862 \mathrm{~Hz} / \text { pixel }\end{array}$ \\
\hline $3 \mathrm{D}$ & $\begin{array}{l}\text { STARVIBE } \\
\text { (SIEMENS) } \\
\text { Not available for } \\
\text { GE and PHILIPS }\end{array}$ & $1.5 \mathrm{~T}-3 \mathrm{~T}$ & $\begin{array}{l}\text { Free-breathing } \\
3-5 \text { min }\end{array}$ & $\begin{array}{l}\mathrm{FOV}=400 \mathrm{~mm} \\
\text { Matrix }=320 \times 320 \\
\mathrm{SL}=4 \mathrm{~mm}\end{array}$ & Low & $\begin{array}{l}\mathrm{TR}=7.46 \mathrm{~ms} \\
\mathrm{TE}=2.46 \mathrm{~ms} \\
\mathrm{FA}=9^{\circ} \\
\mathrm{BW}=820 \mathrm{~Hz} / \text { pixel }\end{array}$ \\
\hline $3 \mathrm{D}$ & LAVA FLEX (GE) & $1.5 \mathrm{~T}-3 \mathrm{~T}$ & Breath-hold (10s) & $\begin{array}{l}\mathrm{FOV}=260 \mathrm{~mm} \\
\text { Matrix }=128 \times 128 \\
\mathrm{SL}=3 \mathrm{~mm}\end{array}$ & High & $\begin{array}{l}\mathrm{TR}=3.7 \mathrm{~ms} \\
\mathrm{TE}=\min \text { full } \mathrm{ms} \\
\mathrm{FA}=1^{\circ}\end{array}$ \\
\hline $3 \mathrm{D}$ & $\begin{array}{l}\text { PETRA(SIEMENS) } \\
\text { ZTE(GE) } \\
\text { MULTIVANE-XD } \\
\text { (PHILIPS) }\end{array}$ & $1.5 \mathrm{~T}-3 \mathrm{~T}$ & $\begin{array}{l}\text { Free-breathing } \\
7-10 \mathrm{~min}\end{array}$ & $\begin{array}{l}F O V=360 \mathrm{~mm}^{3} \\
\text { Matrix size }=416 \mathrm{~mm}^{3}\end{array}$ & Low & $\begin{array}{l}\mathrm{TR}=4.1 \mathrm{~ms} \\
\mathrm{TE}=0.07 \mathrm{~ms}\end{array}$ \\
\hline
\end{tabular}

Adapted from Liszewski et al. [11], with permission

GE General Electric, Boston, Massachusetts, USA, Siemens Munich, Germany, Philips Amsterdam, Netherlands

Table 1.1 provides an outline of MR imaging sequences commonly used to image the lungs and pleura [11].

\section{Anatomy}

\section{Embryology}

Lung Development The development of the lung begins in the first gestational month and continues after birth into childhood. The development is divided into five phases: embryonic, pseudoglandular, canalicular, saccular, and alveolar.

Phases of Prenatal Lung Development During the fourth week of gestation, lung development begins when the laryn- gotracheal groove arises from the foregut endoderm and forms the lung bud. The embryonic phase begins when the lung bud divides into the right and left bronchial buds [12]. In the embryonic phase, the bronchial buds lengthen and divide into three branches on the right and two branches on the left and further subdivide into the pulmonary segments. By the end of the embryonic phase, a vascular plexus begins to form within the lung mesenchyme [13] (Fig. 1.1).

The pseudoglandular phase begins at week 5 and ends at week 17. In this phase, the bronchi further divide, and by week 17, the entire air-conducting portion of the lung has developed to the level of the terminal bronchiole. On the cellular level, ciliated, goblet, and neuroendocrine cells develop, and the terminal bronchioles contain cuboid columnar cells (see Fig. 1.1). 


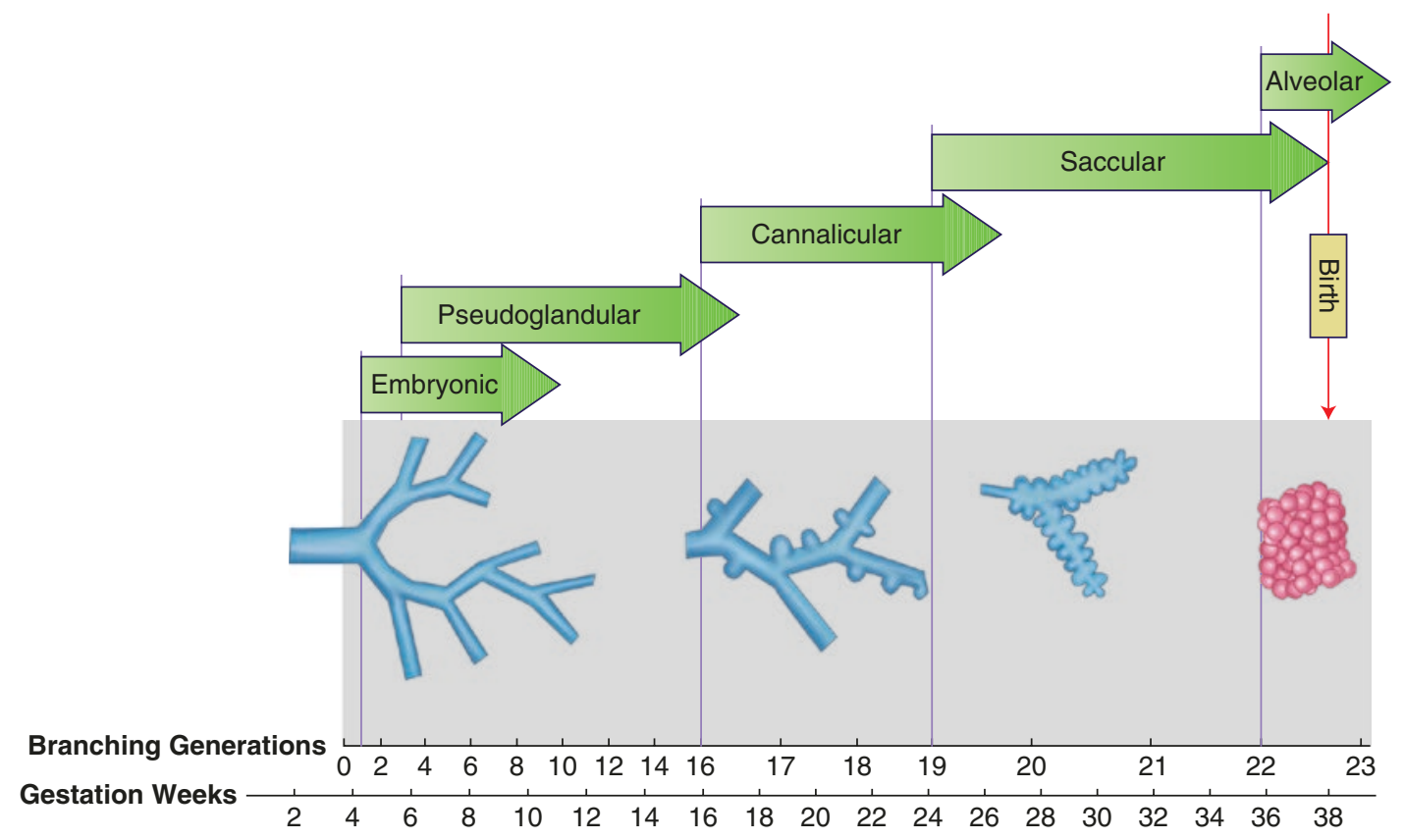

Fig. 1.1 Diagram showing prenatal lung development

The canalicular phase begins at week 17 and ends at week 28. The portion of the lung involved in oxygen exchange develops during this phase, including the respiratory bronchioles, alveolar ducts, and alveoli. Type I pneumocytes begin to develop in this phase, and Type II pneumocytes contain surfactant proteins but do not secrete them. The alveolar capillary bed begins to form at this stage. By the end of the canalicular phase, gas exchange is possible, and survival outside the uterus is feasible, but only with intensive medical care, exogenous surfactant therapy, and mechanical ventilation (see Fig. 1.1).

The saccular phase begins at week 29 and ends at week 36. Alveolar sacculi proliferate during this phase, and the basal lamina of the distal respiratory epithelium fuses with the basal lamina of the alveolar capillary endothelium, allowing for improved gas exchange. Surfactant begins to be excreted during this phase, but its production is not yet at the levels of a full-term newborn, and children born at this phase usually require exogenous surfactant therapy [14] (see Fig. 1.1).

The alveolar phase begins at week 36 and continues through 18 months of age. Throughout this phase, more alveoli form, leading to approximately 50 million alveoli soon after birth and 300 million alveoli by the time the lung is fully mature. With alveolar development, the pulmonary alveolar capillary network also grows, leading to increased capacity for gas exchange [15] (see Fig. 1.1).

Fetal Lung Fluid and Surfactant Fetal lung fluid fills the airways and alveoli while in utero. Although it mixes with amniotic fluid, the composition of fetal lung fluid is differ- ent than that of amniotic fluid. Fetal lung fluid is produced by the respiratory epithelium. At term, approximately $5 \mathrm{~mL} / \mathrm{kg} /$ hour. of lung fluid is produced [16]. During labor and immediately after birth, fetal lung fluid is cleared by pulmonary lymphatics [17].

Surfactant is composed of phospholipids, protein, neutral lipids, and cholesterol and is found within fetal lung liquid in the later stages of gestation. Intracellular surfactant is present within Type II pneumocytes in the canalicular phase at 20-24 weeks gestation and can be found within fetal lung fluid starting in the saccular phase [17]. Surfactant produced before 35 weeks gestation is present in smaller amounts and is more susceptible to inactivation than after 35 weeks $[17,18]$. Surfactant allows alveoli to expand during inspiration by reducing surface tension [19, 20]. Surfactant is essential to lung function, and a major complication of pre-term birth is surfactant deficiency disorder (SDD). When a pre-term birth is imminent, pregnant mothers can be treated with glucocorticoids to speed up endogenous surfactant production by the fetus. After birth, exogenous surfactant may be administered via endotracheal tube to treat SDD.

Pleural Development The pleura begins development before the lungs at 3 weeks gestation. At this time, the pleura begins to form from the mesoderm along with the pericardium and peritoneum [21]. At 9 weeks gestation, the pleura separates from the pericardium and peritoneum. The pleura is comprised of the visceral pleural, which covers the lung, and the parietal pleura, which covers the chest wall and diaphragm [21] (Fig. 1.2). 


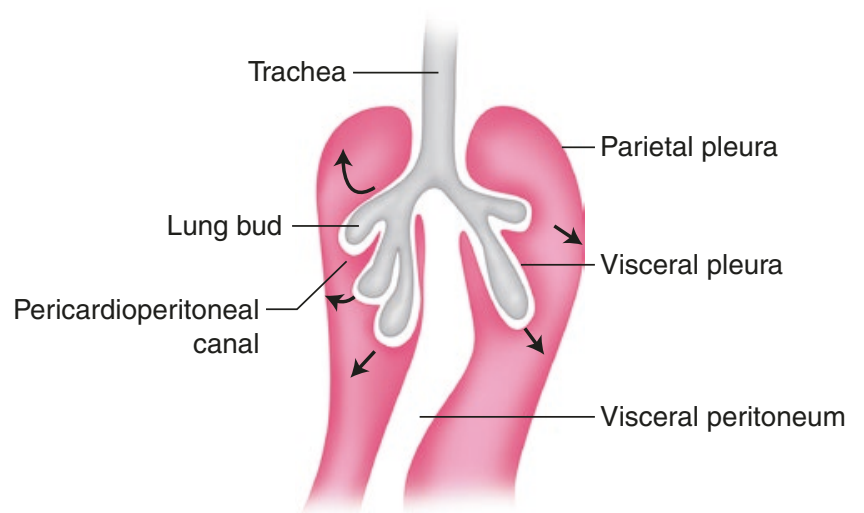

Fig. 1.2 Diagram showing pleural development

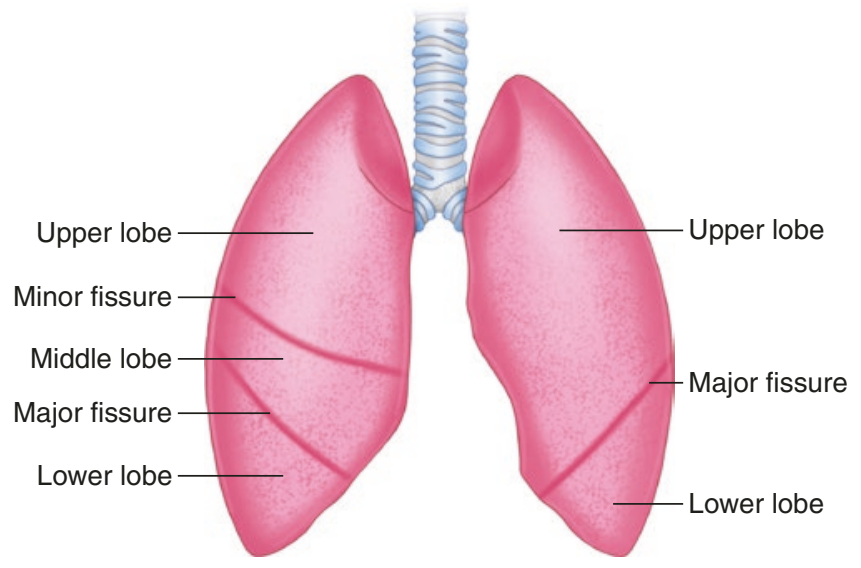

Fig. 1.3 Diagram of lobar anatomy: sections of normal lung

\section{Normal Development and Anatomy}

Lobar Anatomy The right lung is composed of three lobes (upper, middle, and lower), and the left lung is composed of two lobes (upper, which includes the lingua, and lower) (Fig. 1.3). Each lobe is separated by a pleura-lined fissure. Each lobe is further divided into segments, which are defined by segmental bronchi and not divided by fissures. Table 1.2 describes the segments in each lobe.

\section{Lung Parenchyma}

Secondary Pulmonary Lobule The secondary pulmonary lobule is the smallest structural unit of the lung that may be visible on MR imaging; smaller structures such as the pulmonary acini and alveoli are too small to be visualized as discrete structures. Each secondary pulmonary lobule has a polyhedral shape and is bordered by connective tissue septations called interlobular septa (Fig. 1.4). At birth, secondary pulmonary lobules have a mean diameter of $3 \mathrm{~mm}$ and are therefore not visible on most conventional MR imaging sequences. However, they are visible in older children and adults on MR imaging, and they reach a diameter of $13-20 \mathrm{~mm}$ in adulthood
Table 1.2 Lung lobes and segments

\begin{tabular}{|c|c|}
\hline Lobes & Segments \\
\hline Right upper & Apical, posterior, and anterior \\
\hline Right middle & Lateral and medial \\
\hline Right lower & $\begin{array}{l}\text { Superior, medial basal, anterior basal, lateral } \\
\text { basal, and posterior basal }\end{array}$ \\
\hline Left upper & $\begin{array}{l}\text { Apicoposterior, anterior, superior lingular, and } \\
\text { inferior lingular }\end{array}$ \\
\hline Left lower & $\begin{array}{l}\text { Superior, medial basal, anterior basal, lateral } \\
\text { basal, and posterior basal }\end{array}$ \\
\hline
\end{tabular}

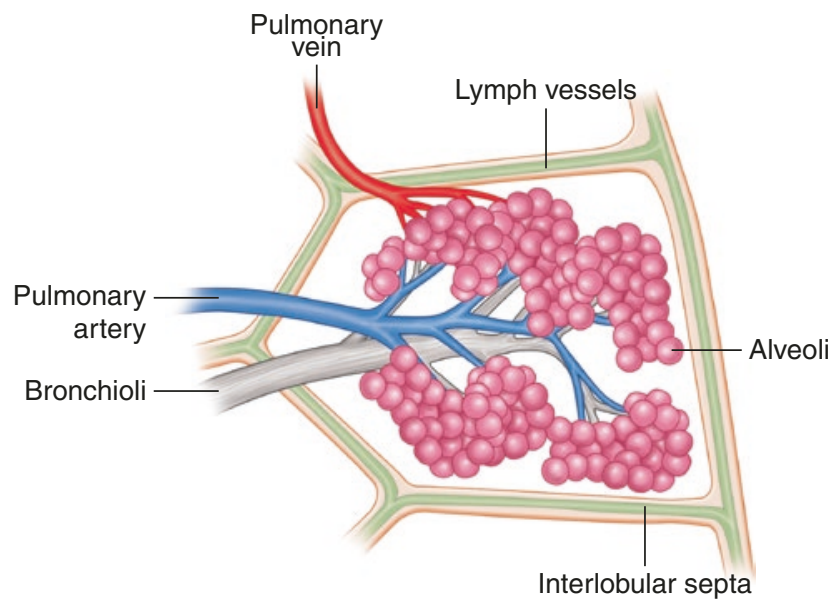

Fig. 1.4 Diagram of lung parenchyma: secondary pulmonary lobule

[22]. A lobular bronchiole is in the center of each secondary pulmonary lobule and communicates with up to 25 terminal bronchioles and their acini [23, 24].

Acini and Alveoli Acini and alveoli are the functional units of the lung where gas exchange occurs. These structures are too small to be visualized as discrete structures on MR imaging. Each lobular bronchiole communicates with up to 25 terminal bronchioles, which communicate with acini and alveoli [23, 24] (Fig. 1.5). When filled with air, groups of acini and alveoli appear uniformly hypointense, and when filled with fluid or other material, they appear uniformly intense because the alveolar walls are beyond the spatial resolution of MR imaging.

Vascular Anatomy Deoxygenated blood moves through the lungs to the alveolar capillaries via the pulmonary arteries, which travel along with bronchi and bronchioles in bronchovascular bundles. The smallest pulmonary arterial branch that can be visualized on MR imaging is the lobular artery which travels in the center of the secondary pulmonary lobule along with the lobular bronchiole. Lobular arteries branch into intralobular and acinar arteries which are beyond the spatial resolution of MR imaging. These small pulmonary artery branches supply an extensive alveolar capillary bed, where gas exchange occurs. Oxygenated blood then enters pulmonary venules, 


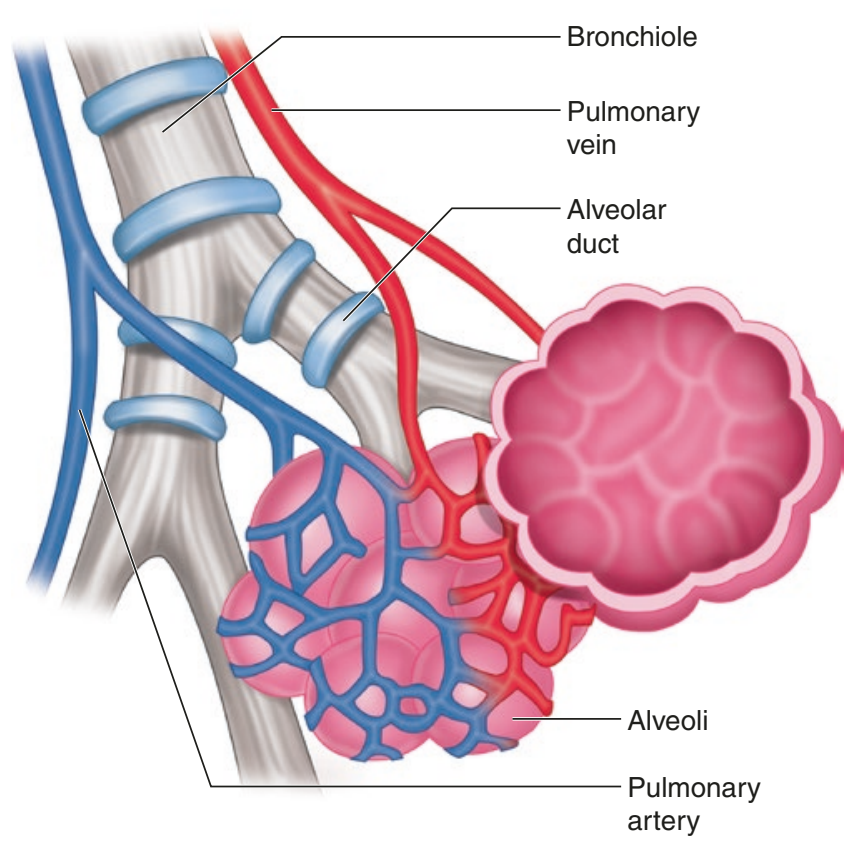

Fig. 1.5 Diagram of acini and alveoli: structure of the lung

which are located within the interlobular septa, separate from the bronchovascular bundles. Pulmonary arteries and veins therefore travel separately, except in the hila where they are adjacent to one another.

A small amount of oxygenated blood is supplied to the lung via bronchial arteries to provide oxygen to the metabolically active tissues in the trachea, bronchi, and pulmonary arteries [9]. Venous drainage of these structures is primarily via systemic bronchial veins, which continue to the right side of the heart via hemiazygous and azygous veins.

Lymphatic Anatomy Pulmonary lymphatics are comprised of a deep plexus and superficial plexus [25]. The deep plexus is located within the bronchovascular bundles in the center of the secondary pulmonary lobule. The superficial plexus travels alongside pulmonary venules within the interlobular septa $[23,25]$.

\section{Pleural Anatomy}

Parietal and Visceral Pleura The pleural space is formed by two pleural membranes: the parietal pleura and the visceral pleura (Fig. 1.6). Each is comprised of a single layer of mesothelial cells, a basement membrane, and a layer of connective tissue which contains blood vessels and lymphatics [21]. The arterial supply to the parietal pleura is via the intercostal arteries, and the visceral pleura is supplied by bronchial arteries. Normal pleural fluid is produced from systemic pleural arteries in both the visceral and parietal pleura [21].

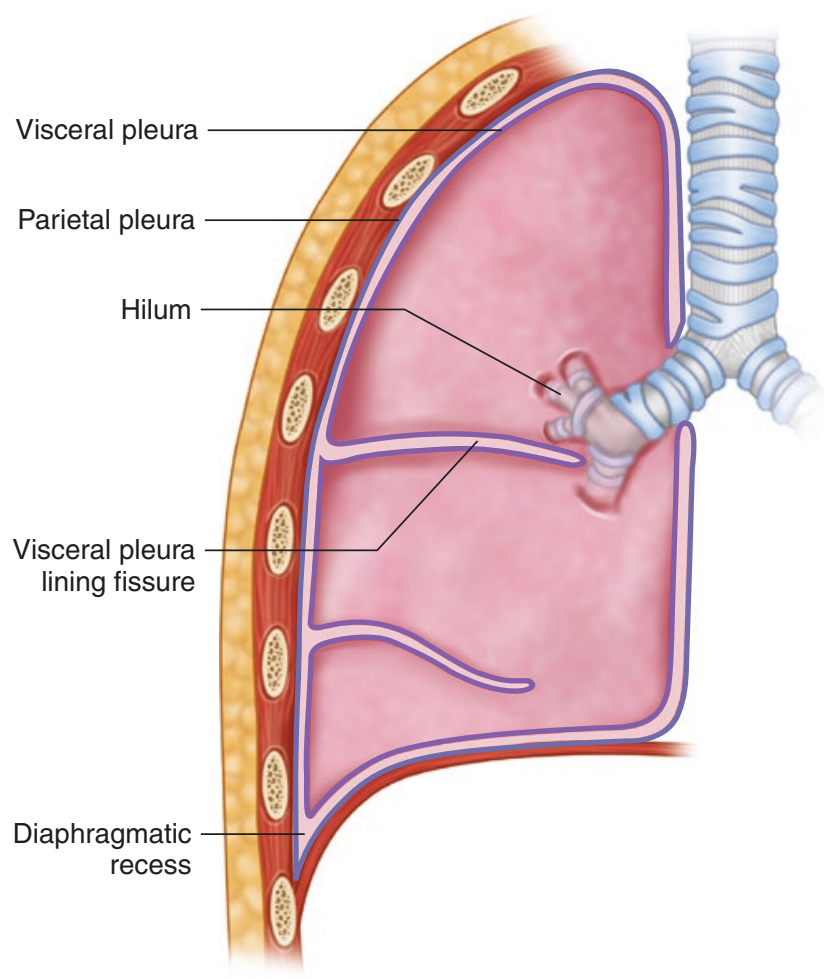

Fig. 1.6 Diagram of pleural anatomy: parietal and visceral pleura

The visceral and parietal pleura both have extensive lymphatic channels. Fluid within the pleural space drains via parietal pleural lymphatics, but not visceral pleural lymphatics [21].

Pleural Fissures The visceral pleura is tightly adherent to the surface of the lung parenchyma and forms the pleural fissures where it invaginates between lobes of the lung (see Fig. 1.6). The right lung contains a major fissure which separates the right lower lobe from the right upper and middle lobes and a minor fissure, which separates the right upper lobe and the right middle lobe. The left lung contains only a major fissure, which separates the left upper lobe and left lower lobe.

\section{Anatomic Variants}

Accessory Pleural Fissures and Lobes Accessory pleural fissures and lobes are relatively common normal variants, seen in approximately $30 \%$ of the population [26, 27]. Accessory fissures include (in order of frequency) inferior accessory fissure (12-21\%), left minor fissure (8-9\%), superior accessory fissure (1-5\%), fissure between the medial and lateral segments of the right middle lobe $(2-5 \%)$, fissure between the superior and inferior segments 

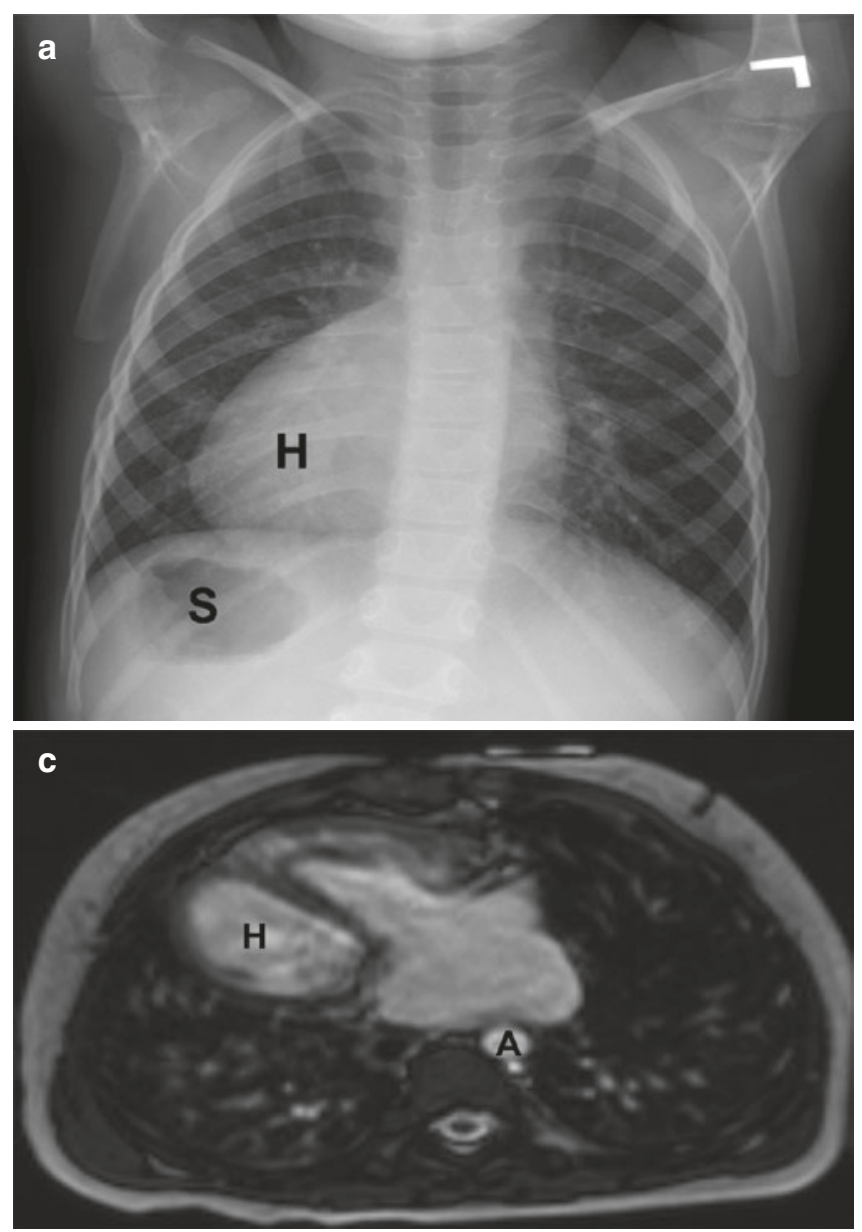

Fig. 1.7 Heterotaxy syndrome in a 4-year-old girl. (a) Frontal chest radiograph shows a right-sided heart $(\mathrm{H})$ and stomach $(\mathrm{S})$. (b) Coronal oblique non-enhanced bright-blood MR image shows right-sided heart (H) and left-sided liver (L). (c) Axial non-enhanced bright-blood MR
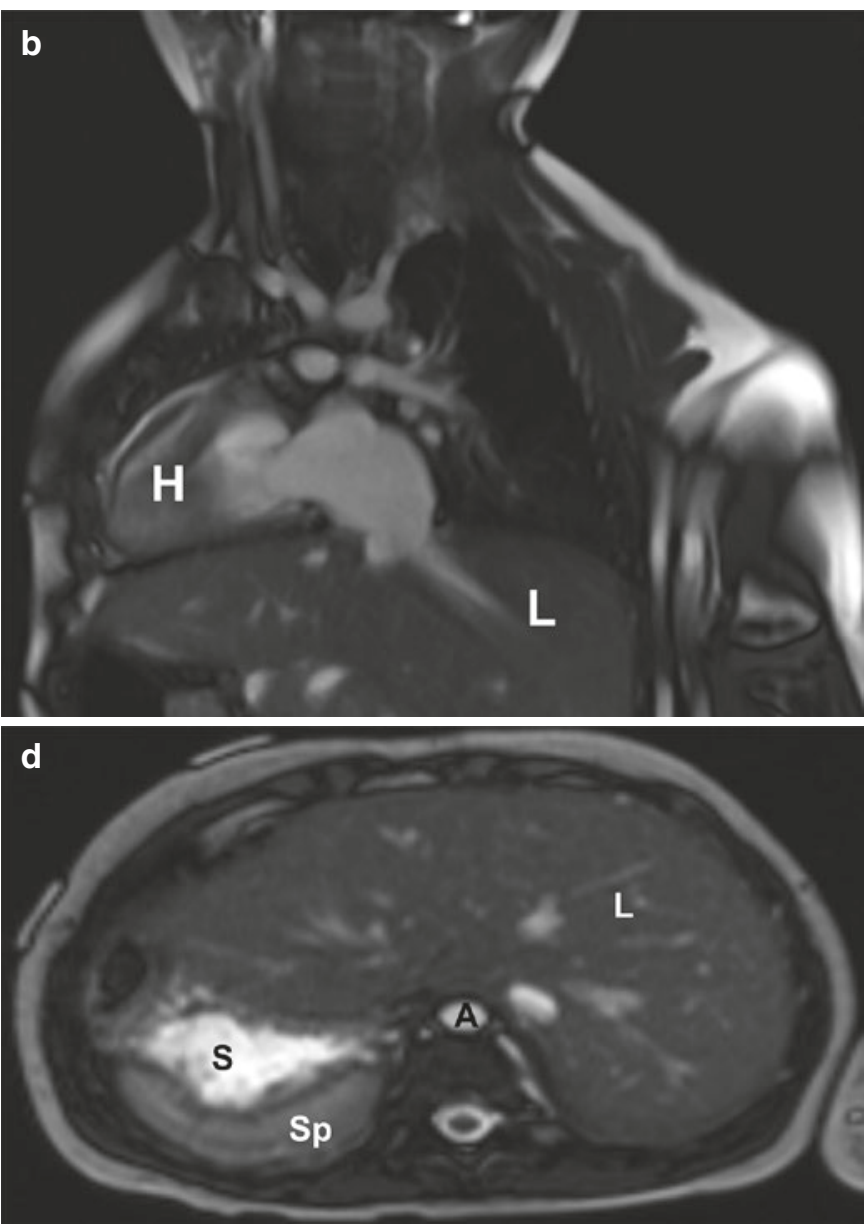

image shows right-sided heart $(\mathrm{H})$ and left-sided descending thoracic aorta (A). (d) Axial non-enhanced bright-blood MR image shows leftsided liver (L), right-sided stomach (S), right-sided spleen (Sp), and midline abdominal aorta (A) of the lingula (1-5\%), and fissure between the anterobasal and laterobasal lower lobe segments $(2.5-3 \%)$ [26, 27].

The azygous fissure is another type of accessory fissure, but it has a different origin than the other accessory fissures. An azygous fissure forms when the azygous vein takes an anomalous lateral course during development and bisects the right upper lobe. Therefore, the azygous fissure is lined by parietal and visceral pleura, unlike the other fissures, which are composed of only visceral pleura.

Heterotaxy Syndromes Heterotaxy syndromes are a group of conditions in which the location and laterality of structures is altered (Fig. 1.7). The simplest example is situs inversus totalis, where all structures are flipped from left to right. In the lungs, situs inversus totalis manifests as a threelobed left lung and two-lobed right lung. More complex heterotaxy syndromes may occur in which both lungs have three lobes (right isomerism) or both lungs have two lobes (left isomerism). Right isomerism is associated with asplenia and left isomerism is associated with polysplenia.

\section{Spectrum of Lung and Pleural Disorders}

In the following sections, the MR imaging findings in a spectrum of congenital and acquired lung and pleural disorders affecting children are presented. Pertinent clinical features and current treatments are also discussed.

\section{Congenital and Developmental Lung Disorders}

Bronchial Atresia Bronchial atresia is a congenital thoracic lesion characterized by developmental interruption, 
or atresia, of a bronchus. There are two main theories about the underlying etiology of bronchial atresia. The first proposes that an ischemic event after bronchial development leads to obliteration of the bronchus. The second proposes a primary disruption of proximal bronchial bud development affecting only the proximal portion of the bronchus but not affecting the distal portion. In either case, the lung distal to the atretic bronchus does not communicate with the central airway. Pulmonary secretions are unable to pass through the atretic bronchus, and the bronchus distal to the atresia eventually fills with fluid, forming a bronchocele. The lung distal to the atretic bronchus becomes hyperinflated due to a check-valve mechanism or air drift via collateral pathways of aeration [28]. The air within the hyperinflated lung becomes deoxygenated, and the vascularity decreases due to hypoxia-induced vasoconstriction.

Bronchial atresia may be detected on prenatal ultrasound, and prenatal MR imaging may be utilized to characterize the lesion. In utero, amniotic fluid rather than air becomes trapped within the lung distal to the atretic bronchus, and prenatal MR imaging characteristically demonstrates hyperintense hyperexpanded region of the lung on T2-weighted imaging due to trapped fluid [28]. If not detected on prenatal imaging, bronchial atresia may be first detected on chest radiographs. Chest radiograph demonstrates a round or oval perihilar opacity representing the bronchocele often with adjacent lucent overinflated segment of the lung.

Whether detected in utero or on chest radiograph, postnatal cross-sectional imaging is often obtained to further evaluate and confirm bronchial atresia, especially when surgical resection is being considered. In current practice, this is most often achieved with contrast-enhanced CT; however, MR imaging has also been described for this indication. MR imaging depicts the bronchocele as a tubular perihilar structure which is hyperintense on T1- and T2-weighted images and does not enhance on post contrast images [29, 30]. Hyperinflation within the distal lung is not as easily depicted on MR imaging as on CT due to the proton-poor environment within the air-filled hyperexpanded lung [31].

When symptomatic, bronchial atresia is treated with surgical resection. Management of small asymptomatic bronchial atresia is currently controversial, with some recommending resection due to risk of superinfection and others favoring a conservative approach $[32,33]$.

Congenital Lobar Emphysema Congenital lobar emphysema (CLE) or also known as congenital lobar overinfla- tion is characterized by hyperexpansion of a lobe of the lung due to narrowing of a lobar bronchus. CLE occurs in certain lobes more frequently, occurring in the left upper lobe $>$ right middle lobe $>$ right upper lobe $>$ right or left lower lobe [34]. It can also affect more than one lobe. CLE often produces symptoms soon after birth due to progressive lobar hyperexpansion, and treatment consists of lobectomy.

CLE may be detected on prenatal ultrasound, and prenatal MR imaging may be utilized to characterize the lesion. In utero, amniotic fluid rather than air becomes trapped within the hyperexpanded lobe, and prenatal MR imaging characteristically demonstrates hyperintense hyperexpanded lobe of lung on T2-weighted imaging due to trapped fluid. CLE and bronchial atresia have similar findings on fetal MR imaging, and differentiating between the two is often difficult. If not detected on prenatal imaging, CLE may be detected on chest radiographs in the newborn period demonstrating progressive hyperexpansion of a lobe of the lung.

Whether detected in utero or on chest radiograph, postnatal cross-sectional imaging is often obtained to further evaluate, characterize, and confirm CLE, especially when surgical resection is being considered. In current practice, this is most often achieved with CT. MR imaging has a limited role for this indication, because the proton-poor hyperexpanded lung is not as well characterized on MR imaging. With newer imaging techniques that improve MR imaging resolution (such as UTE and ZTE sequences), MR imaging may play a larger role in the future. On MR imaging, CLE appears as a hypointense hyperexpanded lobe of the lung, often with accompanying mediastinal shift and ground-glass signal abnormality within the adjacent lobes due to compressive atelectasis.

Currently, asymptomatic children or those with only mild symptoms are often managed conservatively with continuous follow-up to assess possible interval resolution or stability, whereas lobectomy by open or thoracoscopic approach is employed for symptomatic pediatric patients.

\section{Bronchogenic and Other Foregut Duplication Cysts} Bronchogenic cysts are a type of foregut duplication cyst that occurs due to abnormal budding of the ventral lung bud or abnormal branching of the tracheobronchial tree during lung development. Most bronchogenic cysts develop in close proximity to the central tracheobronchial tree, and most are located within the mediastinum, but approximately $15 \%$ are located within the lung parenchyma (Fig. 1.8) [35]. Esophageal duplication cysts and neurenteric cysts are other types of foregut duplication cysts, which are related to 

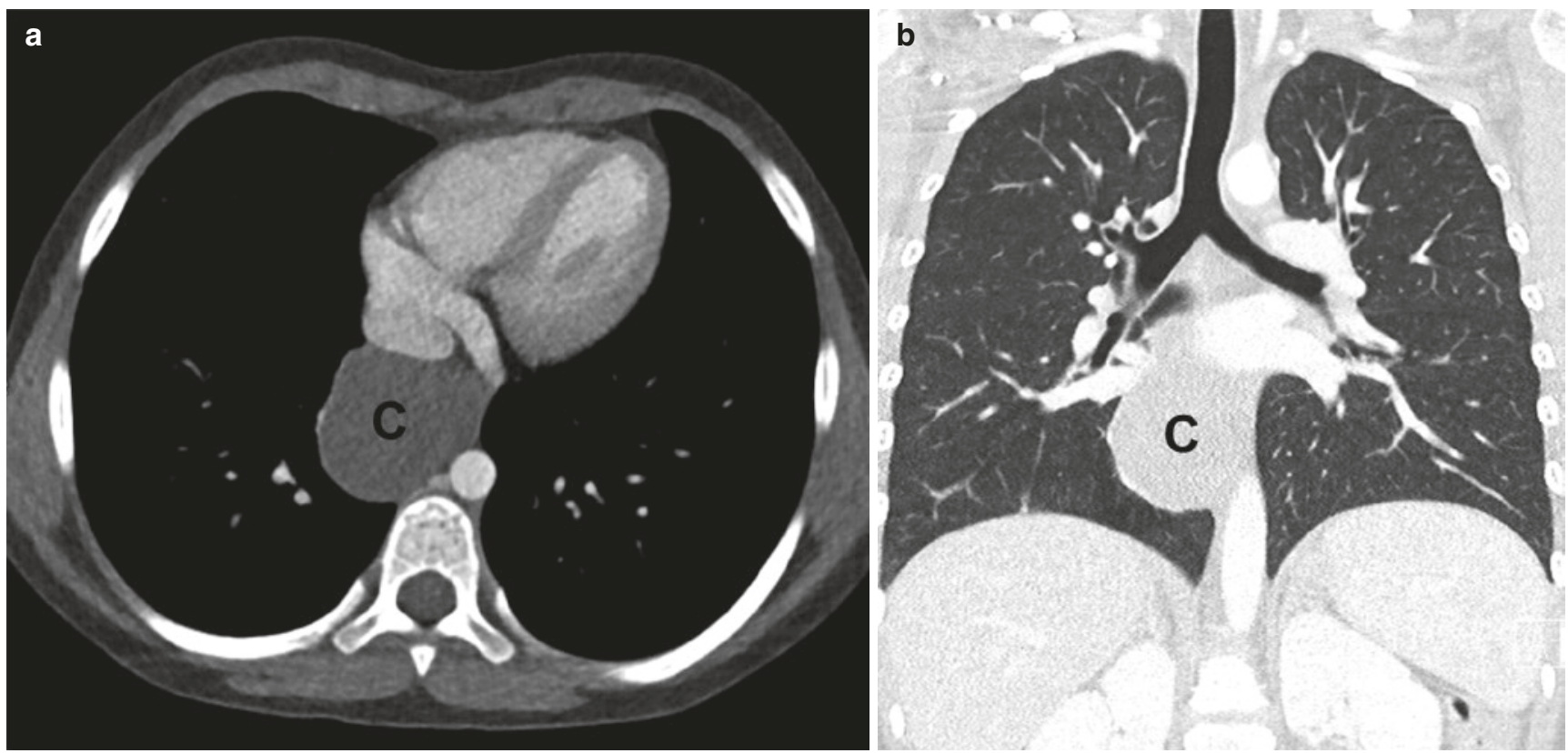

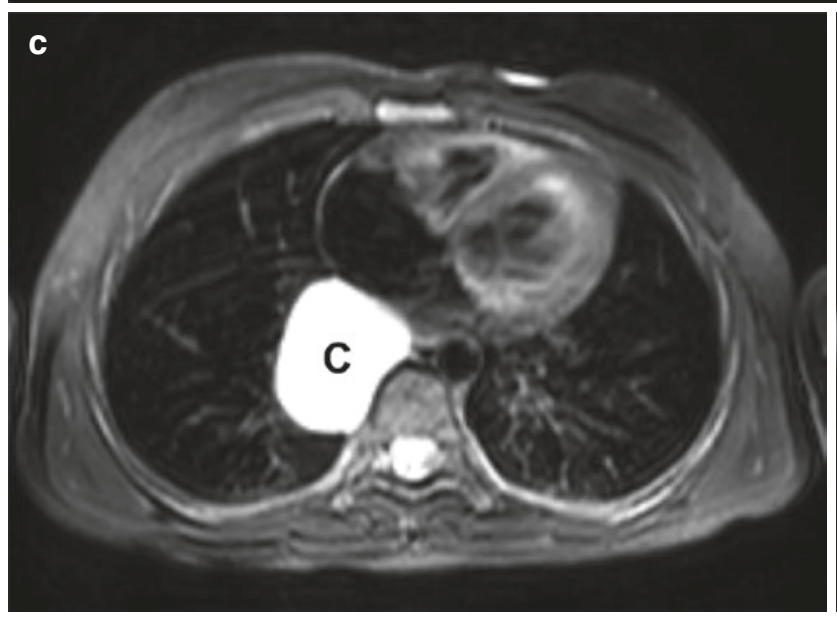

Fig. 1.8 Bronchogenic cyst in a 7-year-old girl. (a) Axial enhanced soft tissue window setting CT image shows a thin-walled cyst (C) in the right posterior mediastinum containing simple fluid density. (b) Coronal enhanced lung window setting CT image shows the thin-walled cyst

bronchogenic cysts (Fig. 1.9). Esophageal duplication cysts arise from the dorsal bud of the primitive foregut, and neurenteric cysts occur due to incomplete separation of the endoderm and notochord. Although often treated as distinct lesions, foregut duplication cysts frequently contain elements of more than one foregut tissue, and hybrid lesions are common.

Bronchogenic and other foregut duplication cysts are most often detected as incidental findings in asymptomatic infants and children. They may be diagnosed on prenatal

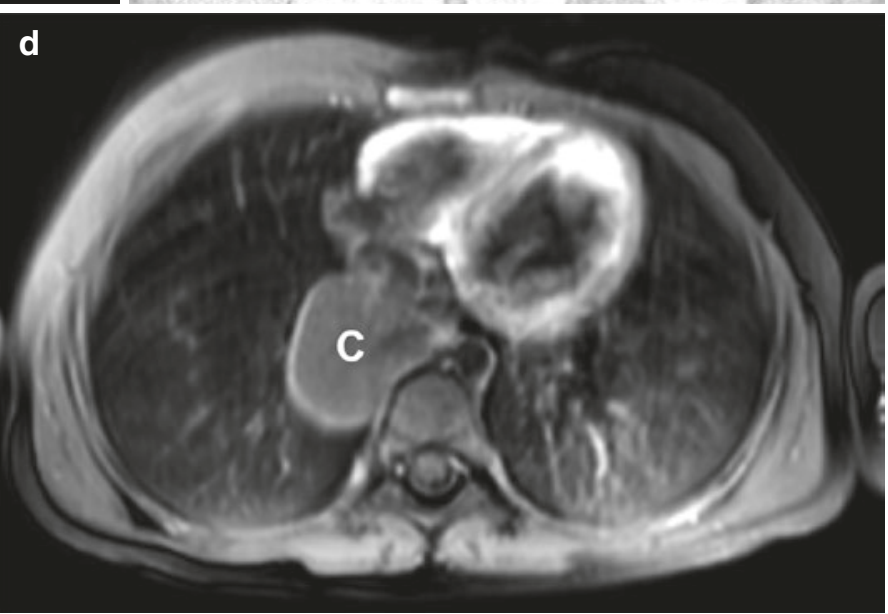

(C). (c) Axial non-enhanced bright-blood short tau inversion recovery (STIR) MR image shows hyperintense signal within the cyst (C). (d) Axial enhanced T1-weighted fat-suppressed MR image shows the cyst (C) with a thin enhancing wall and no central enhancement

imaging, and fetal MR imaging typically demonstrates a unilocular thin-walled hyperintense cyst within the mediastinum on T2-weighted sequences (Fig. 1.10) [36-38]. If not detected prenatally, bronchogenic and other foregut duplication cysts may be detected on chest radiograph as a mediastinal or pulmonary mass. Cross-sectional imaging is often performed to evaluate the finding of a mass. Although this is most typically achieved with CT, MR imaging is an excellent modality to characterize bronchogenic and other foregut duplication cysts. MR imaging 

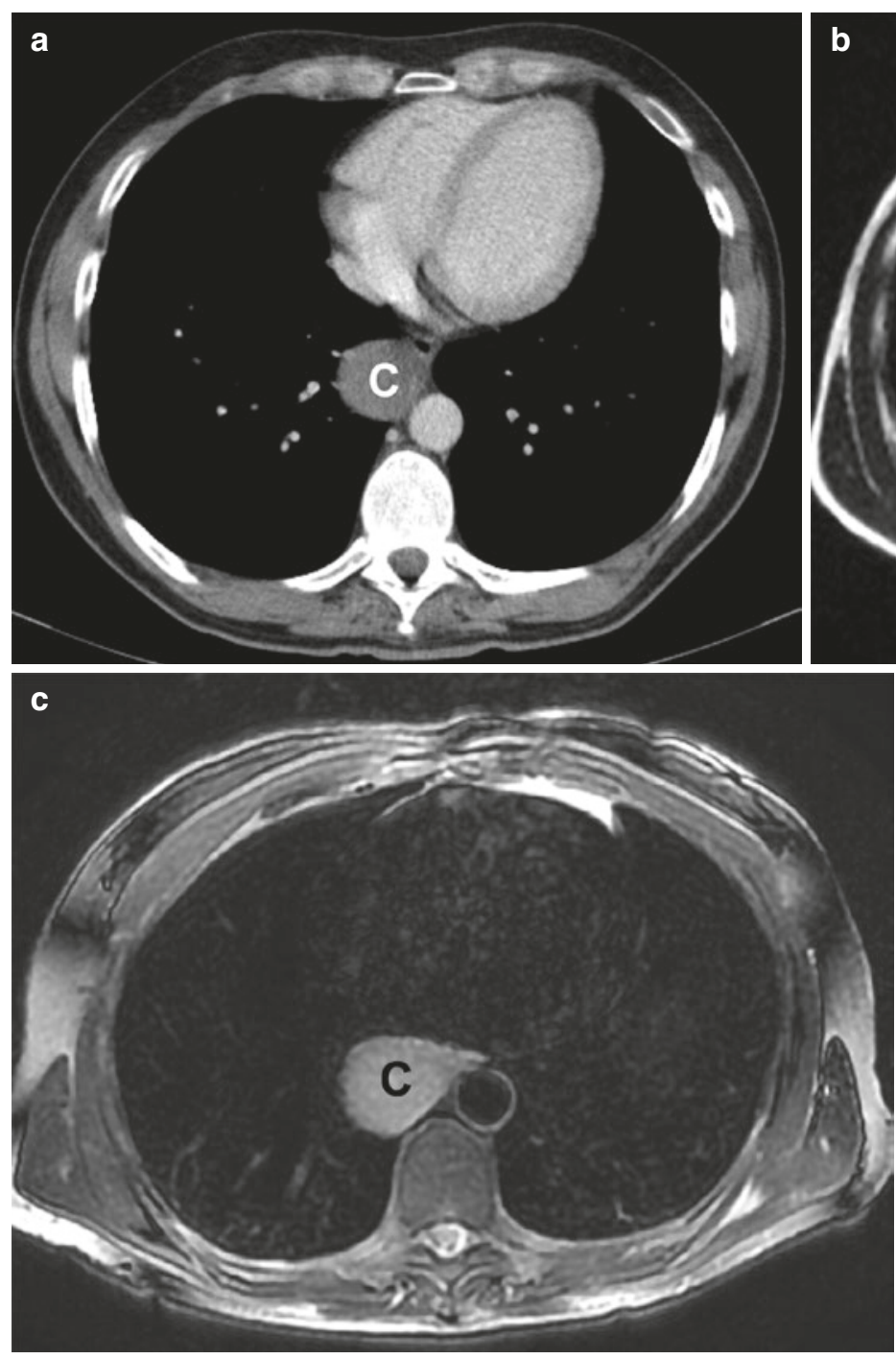
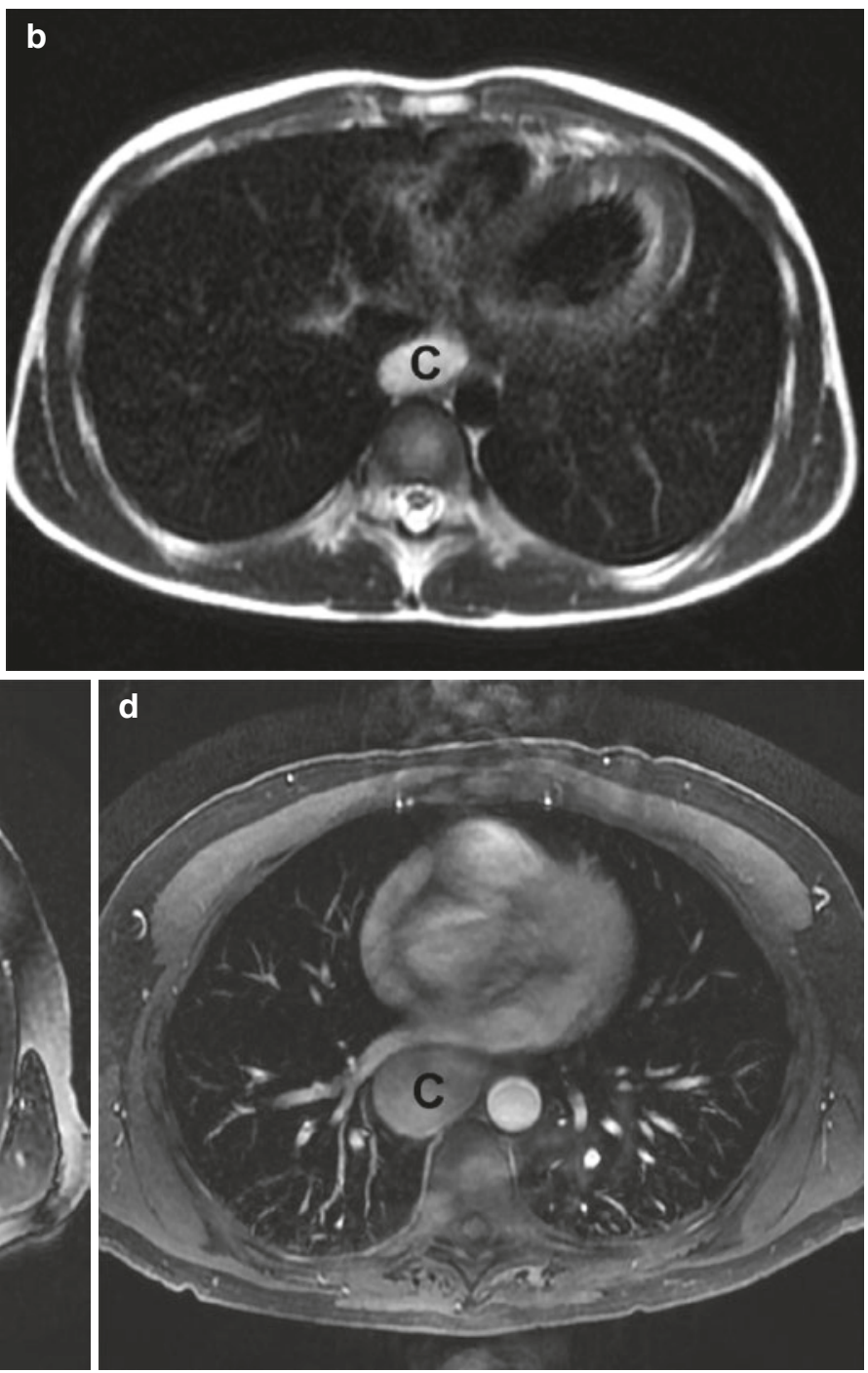

Fig. 1.9 Esophageal duplication cyst in a 12-year-old boy. (a) Axial enhanced soft tissue window setting CT image shows a cyst (C) adjacent to the esophagus which is greater than simple fluid density due to proteinaceous contents. (b) Axial non-enhanced SSFSE T2-weighted MR image shows hyperintense signal within the cyst (C). (c) Axial non- enhanced black-blood T2-weighted MR image shows hyperintense signal within the cyst (C). (d) Axial enhanced T1-weighted fat-suppressed MR image shows the cyst (C) with internal hyperintensity due to intrinsically hyperintense proteinaceous material rather than due to enhancement typically demonstrates a cyst that is hyperintense on T2-weighted images and has variable intensity on T1-weighted images and does not enhance on contrastenhanced images, except for a thin rim of wall enhancement [34]. Bronchogenic cysts within the mediastinum rarely communicate with the airway, but more peripheral cysts may communicate with the airway and contain an air-fluid level [39]. Bronchogenic cysts may become infected, especially when there is communication with the airway. When superinfected, cysts may develop a thick enhancing wall with irregular borders [40].
Currently, both asymptomatic and symptomatic bronchogenic and other foregut duplication cysts are typically treated with surgical resection [40].

Congenital Pulmonary Airway Malformation Congenital pulmonary airway malformations (CPAMs), previously known as cystic adenomatoid malformations (CCAMs), are a group congenital lung lesions composed of large cysts or microscopic cysts, bronchiolar overgrowth, and abnormal connection with the airway [39, 40]. Classically, CPAMs have conventional pulmonary vascular anatomy, 


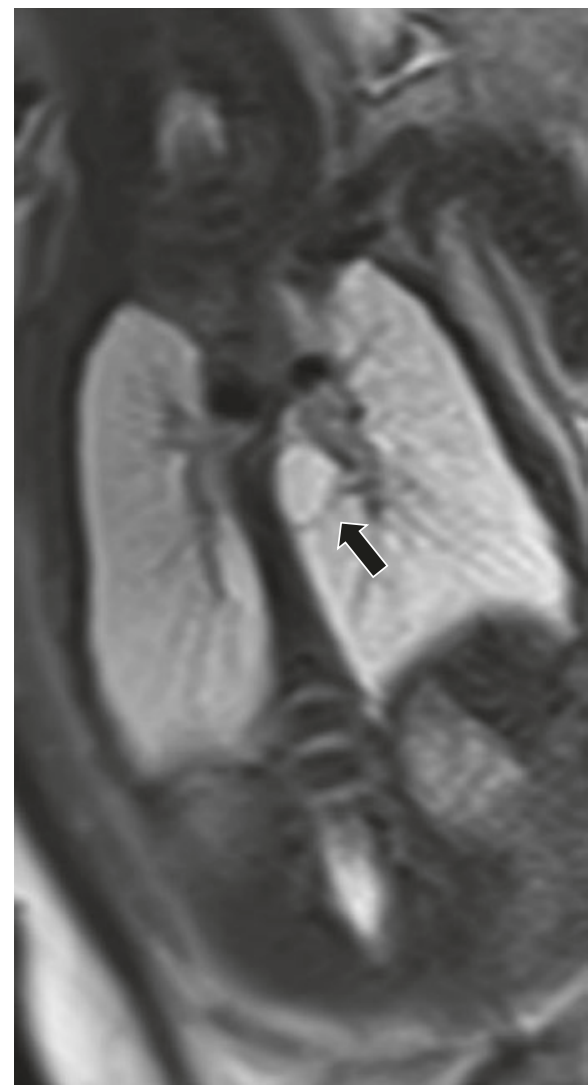

Fig. 1.10 Bronchogenic cyst on prenatal MR imaging. Coronal nonenhanced T2-weighted image shows a thin-walled cyst (arrow) adjacent to the left bronchus

Table 1.3 Congenital pulmonary airway malformation (CPAM) modified Stocker classification

\begin{tabular}{ll} 
Type & Characteristics \\
Type 0 & $\begin{array}{l}\text { Diffuse acinar dysgenesis } \\
\text { Incompatible with life and rarely seen in clinical practice }\end{array}$ \\
Type 1 & Large cyst or cysts measuring $>2 \mathrm{~cm}$ \\
Type 2 & Cyst or cysts measuring $<2 \mathrm{~cm}$ \\
Type 3 & $\begin{array}{l}\text { Tiny “microcysts" measuring }<5 \mathrm{~mm} \\
\text { Appears as a solid mass on imaging and gross inspection }\end{array}$ \\
Type 4 & $\begin{array}{l}\text { Large cysts in the periphery of the lung } \\
\text { Difficult to differentiate from type 1 }\end{array}$ \\
\hline
\end{tabular}

receiving blood from the pulmonary artery and draining to the pulmonary vein [41]. However, hybrid lesions are common, and elements of CPAM are frequently present in pulmonary lesions supplied by a systemic artery [42-44]. Several classification systems have been developed to describe CPAMs, but the most commonly used system in current practice is the modified Stocker system [39, 40, 42, 44-47]. The modified Stocker system is described in Table 1.3 .
CPAMs may be first diagnosed on prenatal imaging. On fetal MR imaging, CPAMs appear as hyperintense lung lesions, and depending on the type discrete cysts may or may not be visible (Fig. 1.11) [48]. Categorization of CPAMs on fetal imaging is slightly different than on postnatal imaging, largely due to the smaller size of the fetus. On fetal imaging, CPAMS are categorized as macrocystic when cysts are $\geq 5 \mathrm{~mm}$ or microcystic when cysts are $<5 \mathrm{~mm}$ [49]. Macrocystic ( $\geq 5 \mathrm{~mm}$ ) lesions on fetal imaging correspond to Stocker Type 1 lesions, and microcystic $(<5 \mathrm{~mm})$ lesions on fetal imaging correspond to Stocker Type 2 lesions [40, 48]. If not detected on prenatal imaging, CPAM may be first visualized on chest radiograph as an air-filled cystic lesion or a solid mass, depending on the type [48].

Postnatal cross-sectional imaging is indicated to further assess CPAM especially when surgical resection is considered. Currently, CT is the modality most often utilized for this indication, but MR imaging can be utilized as an alternative. Because pulmonary sequestration and hybrid lesions are often a differential consideration, MR angiography is indicated to evaluate the vascular supply. MR imaging findings of CPAMs depend on the type. Cysts in type 1,2, and 4 lesions are air-filled or fluid-filled and have a thin hyperintense wall that enhances on contrastenhanced images (Fig. 1.12) [31]. Type 3 lesions appear as solid enhancing masses on contrast-enhanced MR images.

If a CPAM is causing symptoms, surgical resection is indicated. Management of asymptomatic CPAM is more variable. Many advocate surgical resection due to small risks of superinfection and associated malignancy, but others recommend a conservative approach due to the small incidence of these complications [50-55].

Pulmonary Sequestration Pulmonary sequestration was defined by Pryce in 1946 as "disconnected bronchopulmonary mass or cyst with an anomalous arterial supply" [56]. Twenty-five percent of lesions are defined as extralobar, with their own pleural covering and venous drainage to a systemic vein [39-41]. Seventy-five percent of lesions are defined as intralobar, sharing a pleural covering with the normal lung and with venous drainage to the left atrium [39-41]. Extralobar sequestration may occur in the lower lobes, within the diaphragm, in the abdomen, or within the mediastinum, and intralobar sequestration most often occurs in the lower lobes [39-41].

Sequestration is often diagnosed on prenatal ultrasound. Fetal MR imaging may be performed to further characterize lesions, which typically demonstrates a lesion that is hyper- 


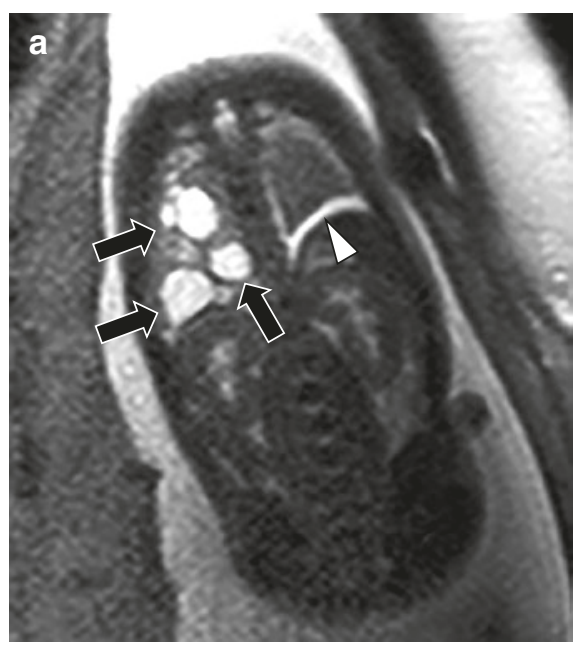

Fig. 1.11 Macrocystic congenital pulmonary airway malformation (CPAM) on prenatal MR imaging. (a) Coronal non-enhanced T2-weighted MR image shows several hyperintense cysts (arrows) in the right lung. A left pleural effusion (arrowhead) is also present. (b)
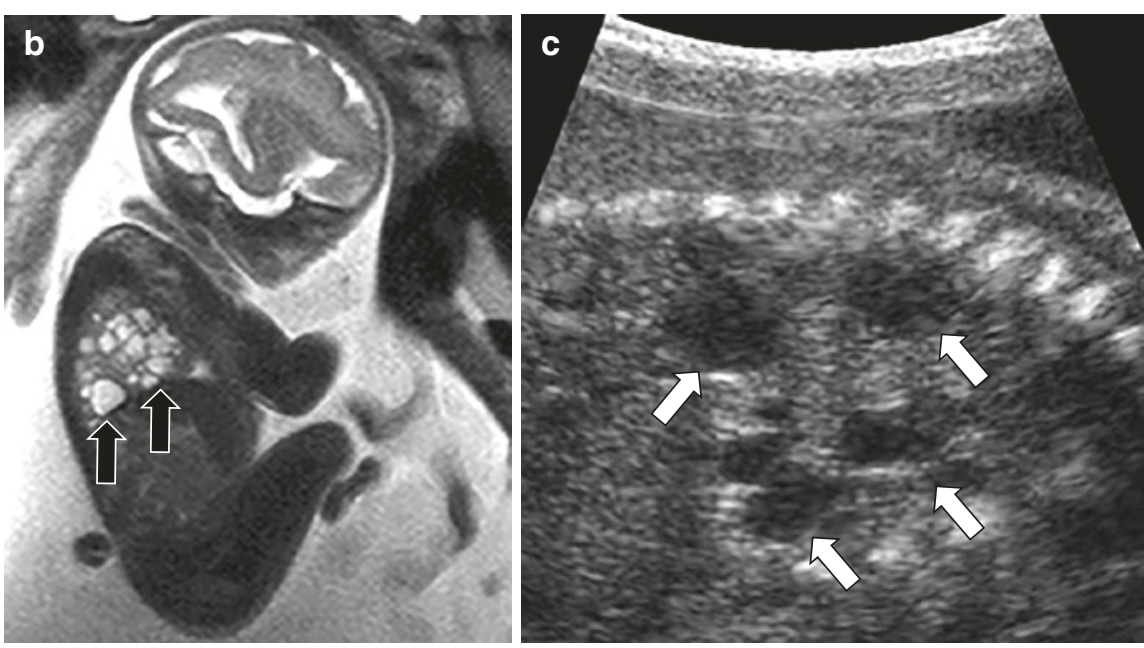

Sagittal non-enhanced T2-weighted MR image shows several hyperintense cysts (arrows) in the lung. (c) Sagittal ultrasound image shows several hypoechoic cysts (arrows) in the lung

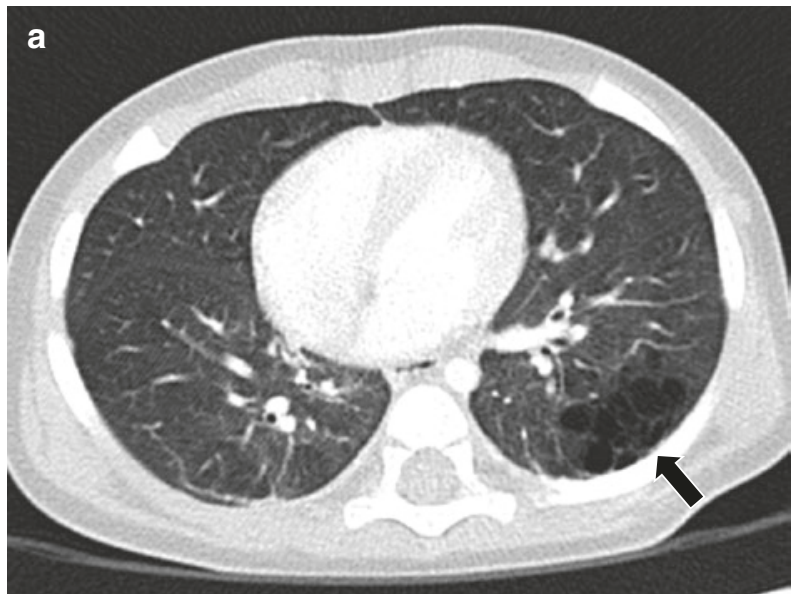

Fig. 1.12 Congenital pulmonary airway malformation (CPAM) type 2 in a boy at 7 months old and 9 years old. (a) Axial enhanced lung window setting CT image at 7 months of age shows multiple cysts

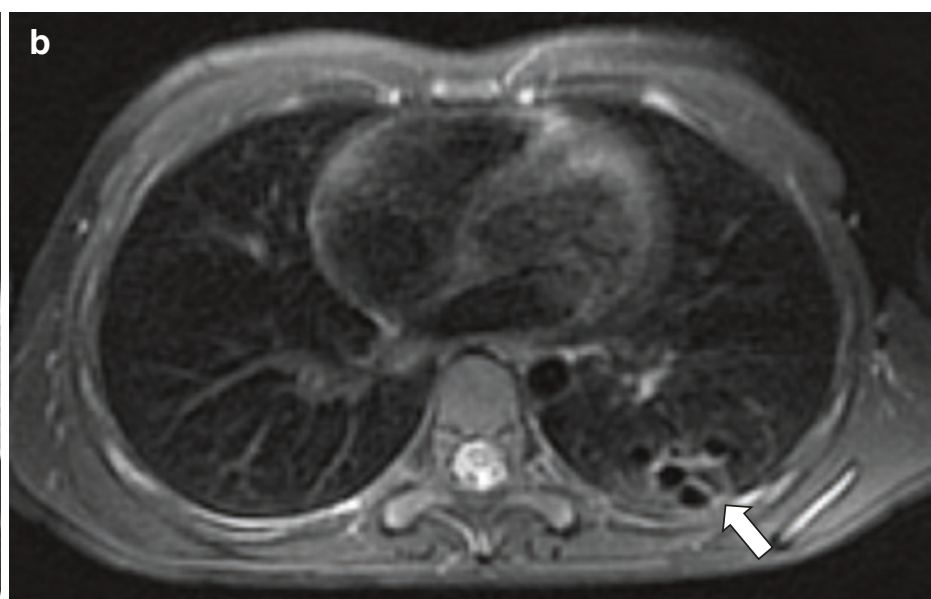

(arrow) measuring $<2 \mathrm{~cm}$ in the left lower lobe. (b) Axial enhanced T1-weighted fat-suppressed PROPELLER MR image at 9 years of age shows multiple cysts (arrow) measuring $<2 \mathrm{~cm}$ in the left lower lobe intense on T2-weighted images (Figs. 1.13 and 1.14). A flow-void might be seen arising from the aorta, indicating the systemic arterial supply, but this is often difficult to visualize. Therefore, the MR imaging appearance may be similar to other lesions including CPAM, bronchial atresia, and congenital lobar emphysema [48, 49, 57].

After birth, cross-sectional imaging is often indicated, especially when surgical resection is considered. CTA is most often performed for this indication given its excellent temporal and spatial resolution and ability to visualize anomalous vasculature. MRA may be appropriate in certain cases, such as if there is heightened concern about the effects of ionizing radiation. The key to imaging pulmonary seques- tration is defining the arterial supply and the venous drainage. On conventional fluid-sensitive MR imaging sequences, sequestration typically appears as a cystic or solid lesion within the lung [31]. MRA demonstrates the systemic feeding artery (usually from the aorta) and the venous drainage to the left atrium (intralobar sequestration) or a systemic vein (extralobar sequestration) [31].

If symptomatic, pulmonary sequestration is treated with surgical resection. Similar to CPAM, management of asymptomatic pulmonary sequestration is somewhat controversial. Treatment may include resection due to concern about superinfection and small risk for malignancy or a watchful waiting strategy $[58,59]$. 
Fig. 1.13 Intralobar pulmonary sequestration on prenatal imaging. (a) Coronal non-enhanced T2-weighted

MR image shows

hyperintense lesion (S)

replacing the right lower lobe and crossing the midline.

(b) Sagittal non-enhanced

T2-weighted MR image

shows hyperintense lesion (S)

replacing the right lower lobe.

(c) Sagittal ultrasound image

with color Doppler shows an

anomalous systemic artery

(arrow) arising from the

descending thoracic aorta.

(d) 3D reconstructed

ultrasound image shows an

anomalous systemic artery

(arrow) arising from the

descending thoracic aorta
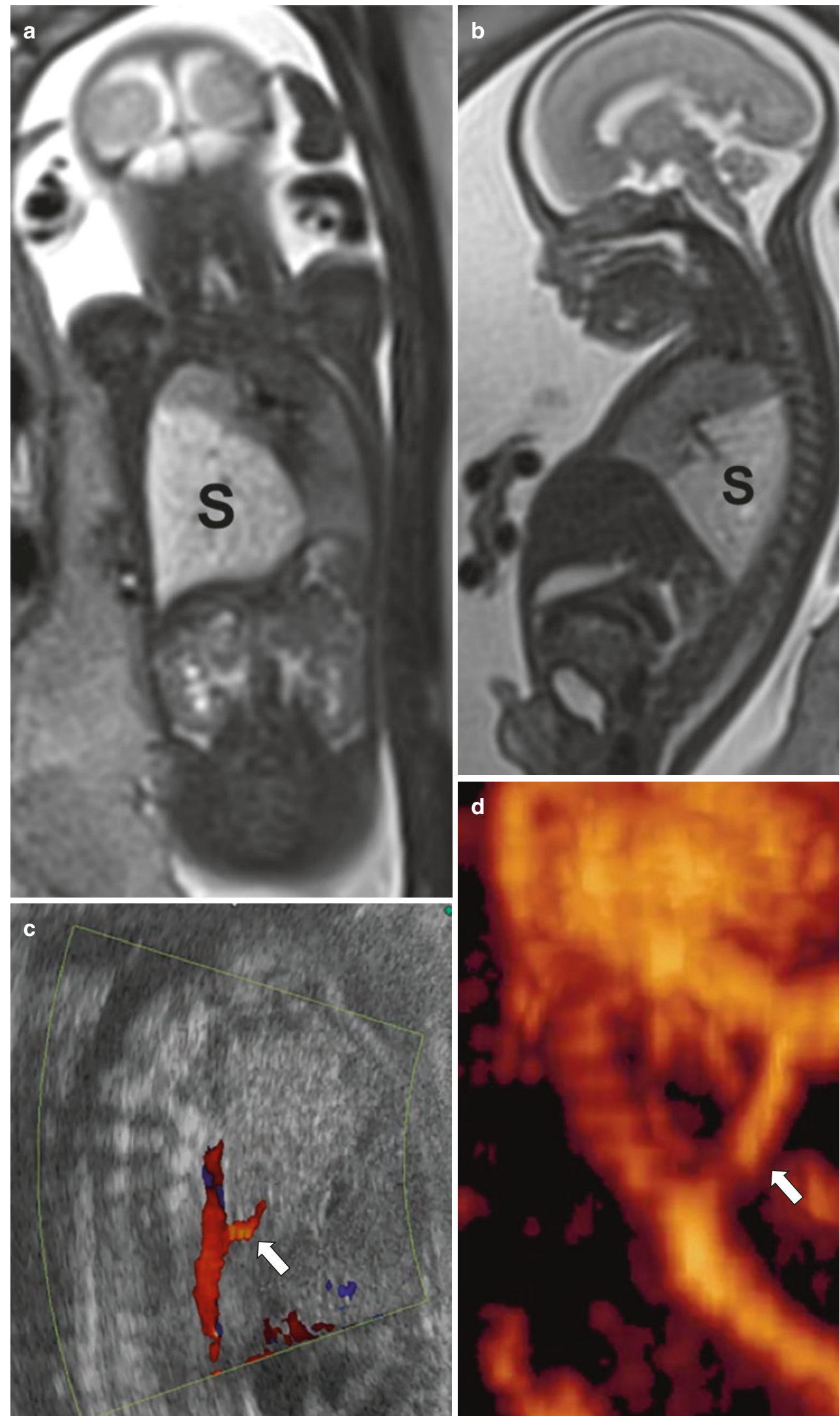


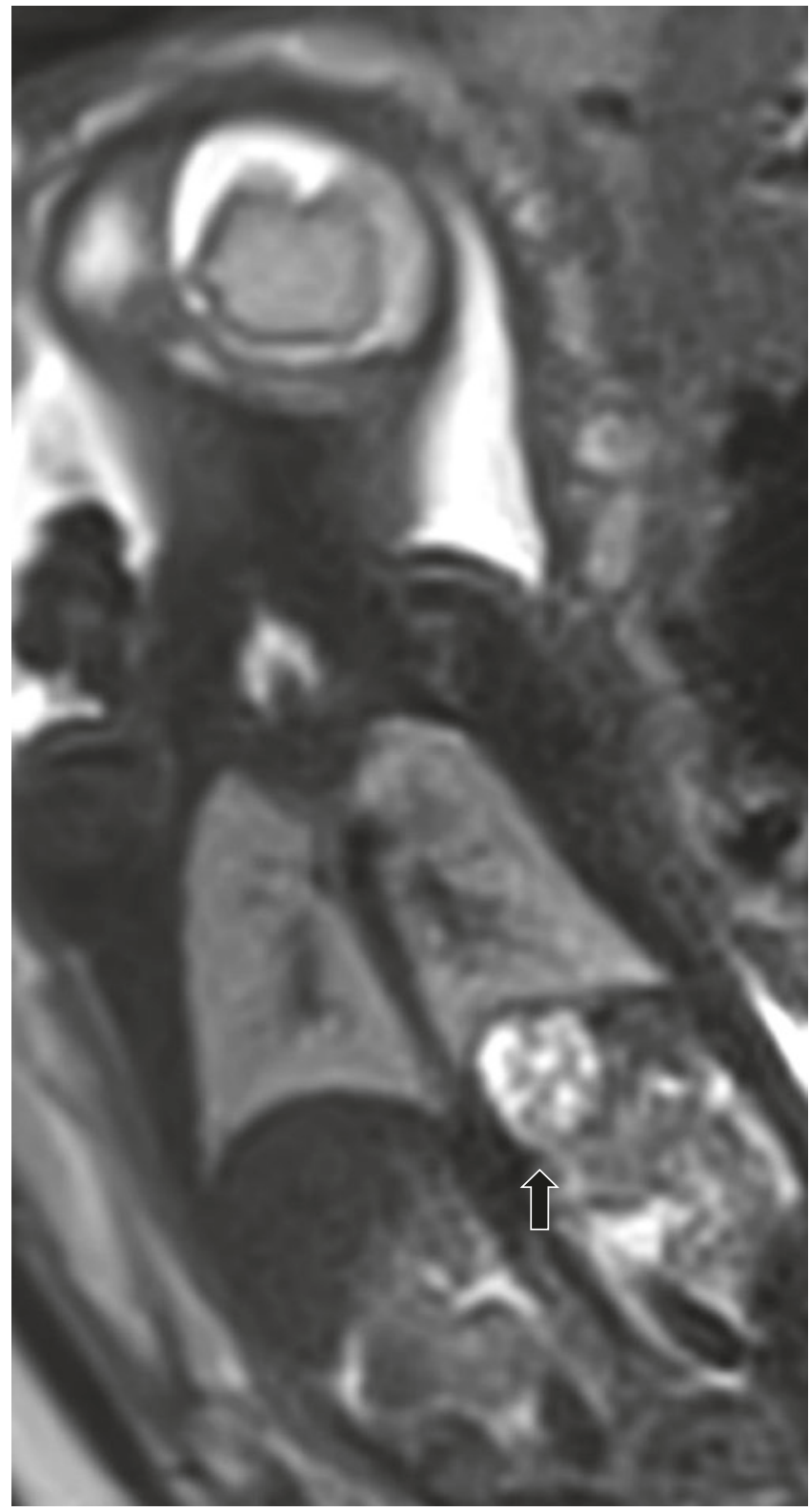

Fig. 1.14 Extralobar infradiaphragmatic pulmonary sequestration on prenatal MR imaging. Coronal non-enhanced T2-weighted MR image shows hyperintense lesion (arrow) inferior to the left diaphragm

\section{Infectious Lung and Pleural Disorders}

Infections of the lungs and pleura are among the most common reasons for children to require medical attention [60, 61]. Imaging is often performed in these children, most commonly beginning with chest radiographs. When complicated infection is suspected, cross-sectional imaging tests are often performed, frequently CT. With increased concern about the potentially harmful effects of ionizing radiation, and technical advances allowing for diagnostic MR imaging imaging of the thorax, MR imaging has begun to gain attention as a potential alternative to $\mathrm{CT}$ in this scenario. A large number of different infections may affect the lungs and pleura, and there is overlap in the

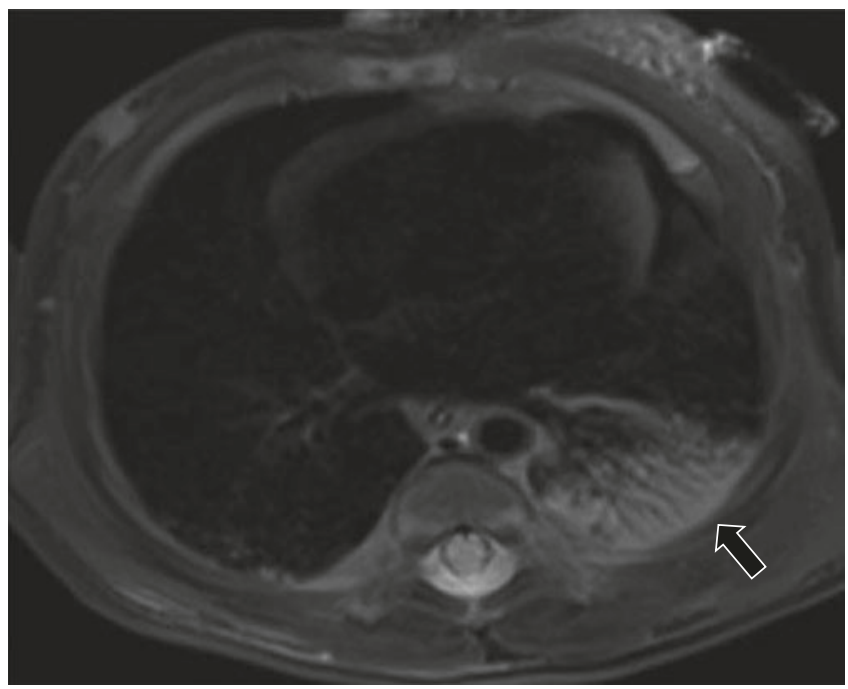

Fig. 1.15 Aspiration pneumonia in a 3-week-old girl who presented with fever and respiratory distress. Axial non-enhanced T2-weighted fat-suppressed MR image shows left lower lobe consolidation (arrow)

imaging features of different infections. In this section, the most frequently encountered pediatric infections of the lungs and pleura are described, and common MR imaging patterns of these infections are illustrated.

Bacterial Infection Bacterial infection of the lung causes pneumonia. Pleural effusion may occur in association with bacterial pneumonia, and empyema occurs if infection spreads to the pleural space. The two most common pathogens to cause bacterial pneumoniain the pediatric population are Streptococcus Pneumoniae and Staphylococcus Aureus. Less common pathogens include Haemophilus Influenzae, Bordetella Pertussis, and Klebsiella Pneumoniae. Other pathogens may occur in specific scenarios, for example, Group B Streptococcus infection in newborn children of colonized mothers, Pseudomonas Aeruginosa infection in pediatric patients with cystic fibrosis, and anaerobic organisms in aspiration pneumonia.

Three main patterns have been recognized in bacterial pneumonia. These include pulmonary consolidation, bronchopneumonia, and atypical pneumonia. Pulmonary consolidation occurs when alveoli fill with exudate, inflammatory cells, and fibrin (Fig. 1.15) [62]. In children consolidation may be lobar or spherical, resulting in "round pneumonia" $[63,64]$. Bronchopneumonia describes a pulmonary infection characterized by peribronchial inflammation affecting multiple lobes and may result in patchy peribronchial consolidation and ground-glass signal (Fig. 1.16). Atypical pneumonia is a condition in which imaging may show only mild pulmonary findings such as mild reticular or patchy opacities without a focal region of consolidation, and symptoms may include headache and sore throat [65]. In current clinical practice, these three patterns are most often seen on chest radiograph or $\mathrm{CT}$, but the findings may also be seen on MR imaging. Detailed descriptions of the specific MR imaging 
findings (e.g., consolidation and ground-glass signal) are covered in a subsequent section.

Pleural effusion may occur in association with bacterial pneumonia and is called parapneumonic effusion (see Fig. 1.16). Empyema occurs when infection spreads to the pleural space, resulting in thickening and hyperemia of the pleural membranes, complex fluid within the pleural space, and loculated pockets of infected fluid. These findings may be appreciated on MR imaging and include hyperintense non-enhancing complex fluid within the pleural space and hyperenhancing thickened parietal and visceral pleura. Rarely, a condition called empyema necessitans can occur when empyema spreads from the pleural space to the chest wall (Fig. 1.17). Empyema

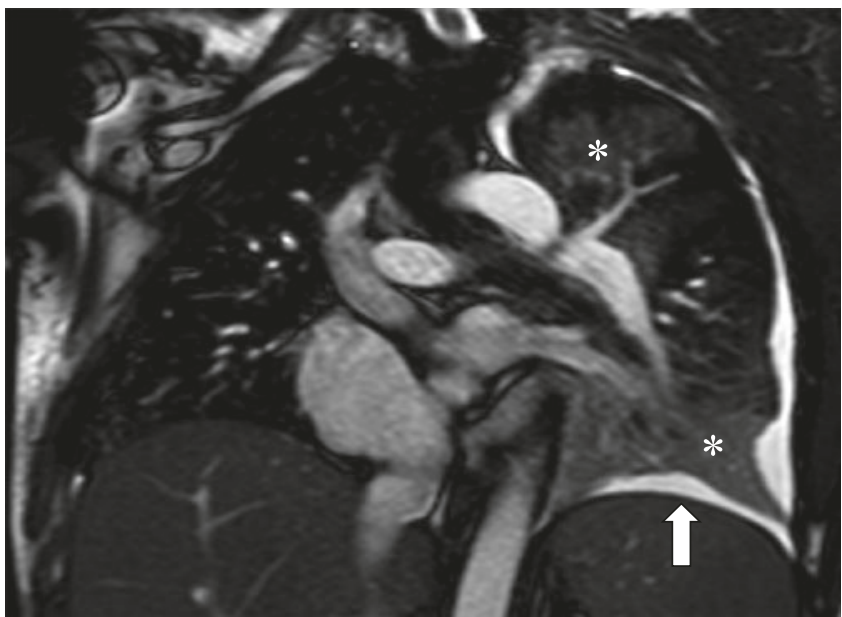

Fig. 1.16 Bacterial bronchopneumonia in a 16-year-old girl who presented with fever and cough. Coronal non-enhanced TruFISP/FIESTA MR image shows peribronchial ground-glass signal abnormality in the left upper and left lower lobes (asterisks) and a simple left pleural effusion (arrow) necessitans is most often caused by Actinomyces israelii or Mycobacterium tuberculosis infection.

Viral Infection Viral respiratory infections include bronchiolitis and viral pneumonia and occur when airborne viruses infect the respiratory mucosa. Infection leads to bronchial wall thickening, inflammation, and mucous production. Mucous plugging and bronchial wall thickening often lead to air trapping and atelectasis. Pleural effusions may accompany viral lower respiratory tract infection. Although these imaging findings are more often described on chest radiograph and $\mathrm{CT}$, the finding may also be appreciated on MR imaging (Fig. 1.18).

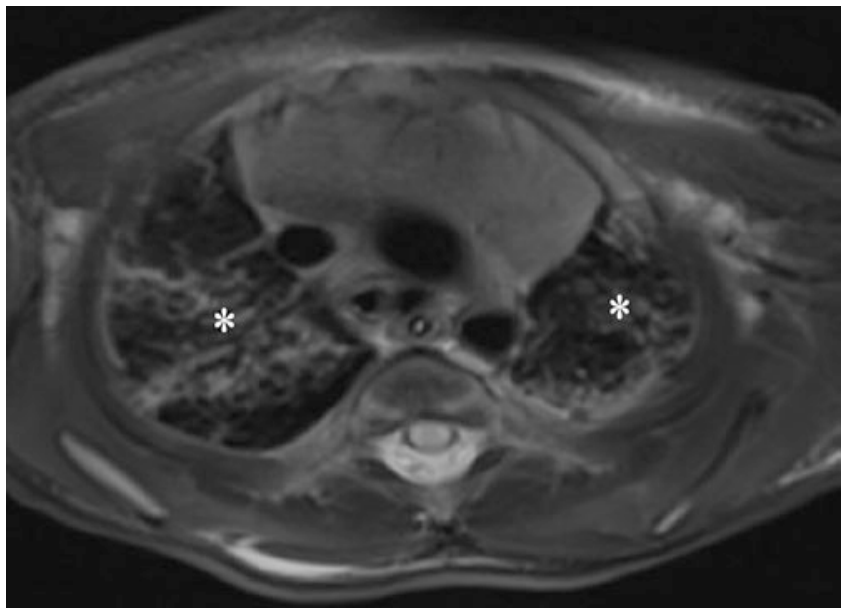

Fig. 1.18 Respiratory syncytial virus infection in a 1-week-old girl who presented with respiratory distress. Axial non-enhanced T2-weighted fat-suppressed MR image shows bilateral peribronchial interstitial thickening (asterisks)
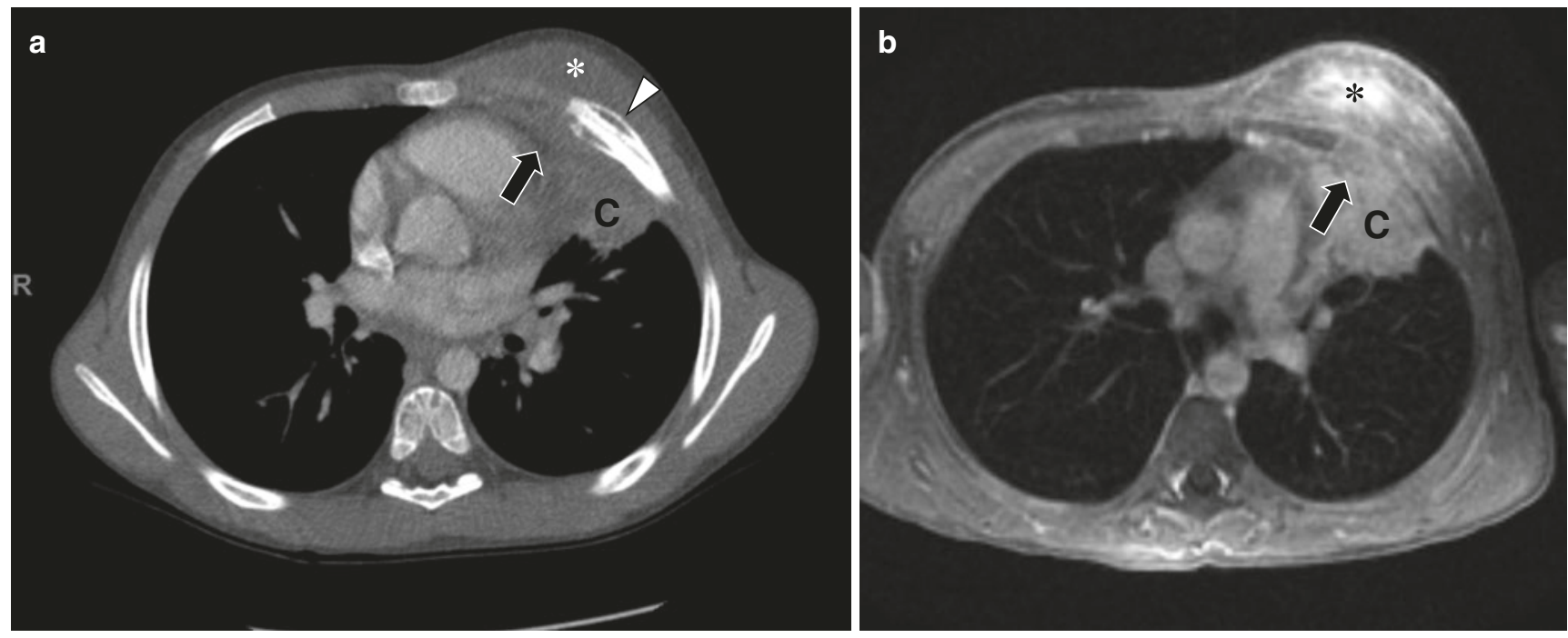

Fig. 1.17 Empyema necessitans in a 17-year-old boy who presented with fever and chest swelling. (a) Axial enhanced soft tissue window setting CT image shows consolidation (C) in the lingua, dense pleural fluid and soft tissue density (arrow), and left chest wall soft tissue thickening and inflam- mation (asterisk) with periosteal reaction (arrowhead) in the adjacent rib. (b) Axial enhanced T1-weighted fat-suppressed MR image shows consolidation $(\mathrm{C})$ in the lingua, pleural soft tissue thickening (arrow), and left chest wall soft tissue thickening and inflammation (asterisk) 
A large number of different viruses may cause lower respiratory tract infection in children. Respiratory syncytial virus (RSV) is the most common cause of viral bronchiolitis in infants and young children (see Fig. 1.18). Other viruses that may result in lower respiratory tract infection include human metapneumovirus, parainfluenza virus, rhinovirus, influenza, adenovirus, and cytomegalovirus, among others.

Fungal Infection Fungal infection of the lungs is uncommon in immunocompetent children but is relatively frequent in immunocompromised children [66]. The most common pulmonary fungal infections are aspergillosis, coccidioidomycosis, and histoplasmosis in the pediatric population. Pulmonary infection most often occurs when airborne fungi enter and disseminate through the lung via endobronchial spread, resulting in multiple pulmonary nodules distributed in a tree-in-bud pattern (Figs. 1.19 and 1.20) [65]. Hematogenous spread also occurs, leading to a pattern of small randomly distributed pulmonary nodules in a "miliary" pattern. Pulmonary nodules in fungal infection often
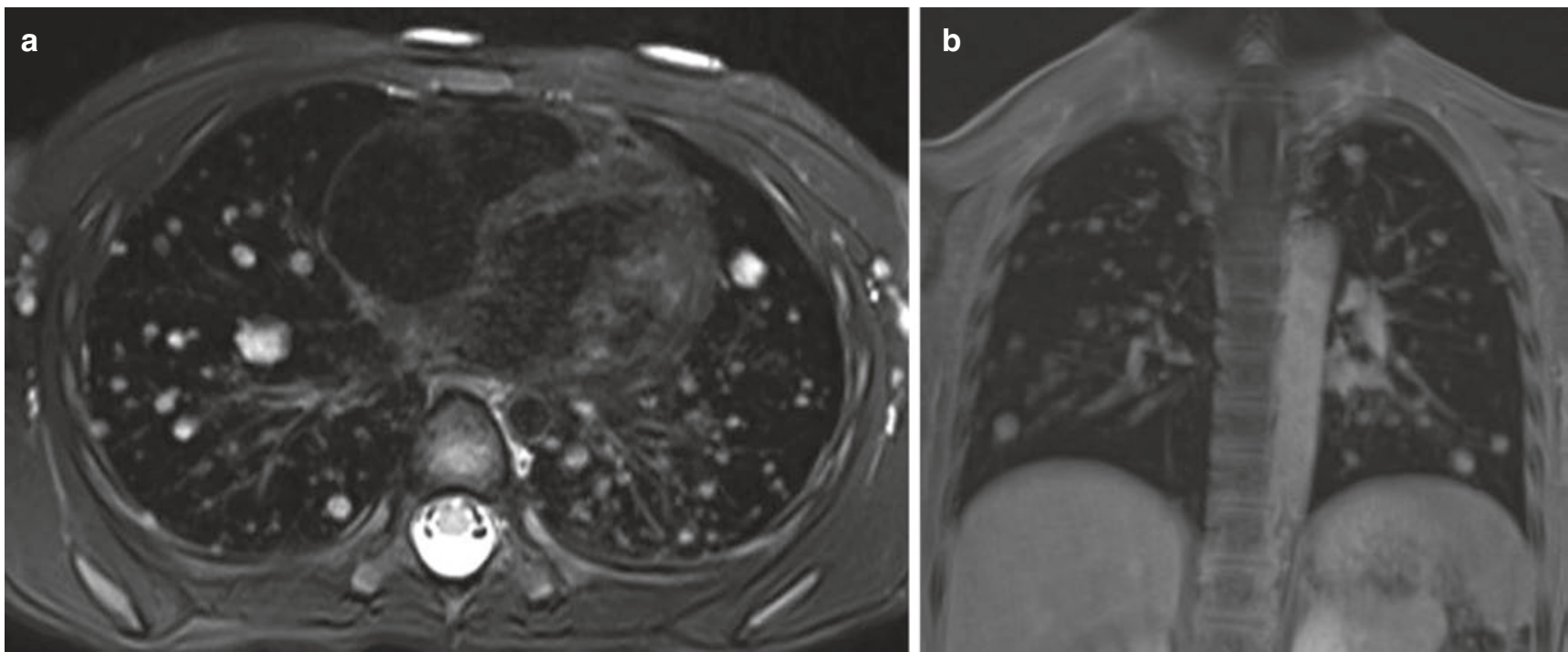

Fig. 1.19 Pulmonary coccidioidomycosis infection in a 5-year-old girl who presented with fever, cough, and headache. (a) Axial non-enhanced T2-weighted fat-suppressed MR image shows numerous bilateral hyperintense pulmonary nodules. (b) Coronal enhanced T1-weighted fat-suppressed MR image shows numerous bilateral hyperintense pulmonary nodules

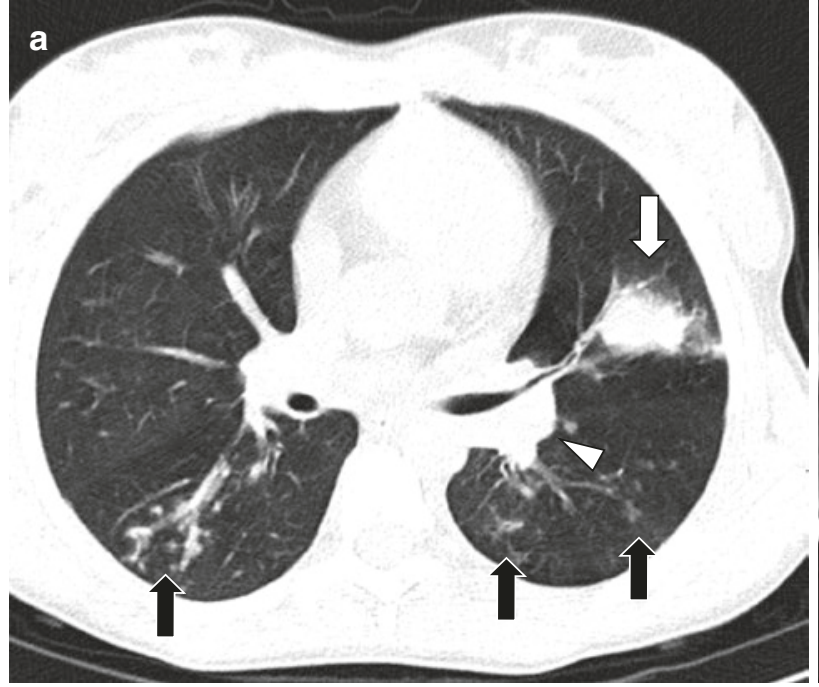

Fig. 1.20 Pulmonary Aspergillus infection in 14-year-old girl with cystic fibrosis. (a) Axial enhanced lung window setting CT image shows tree-in-bud nodularity (black arrows) in bilateral lower lobes, a larger nodule (white arrow) with ground-glass halo in the left upper

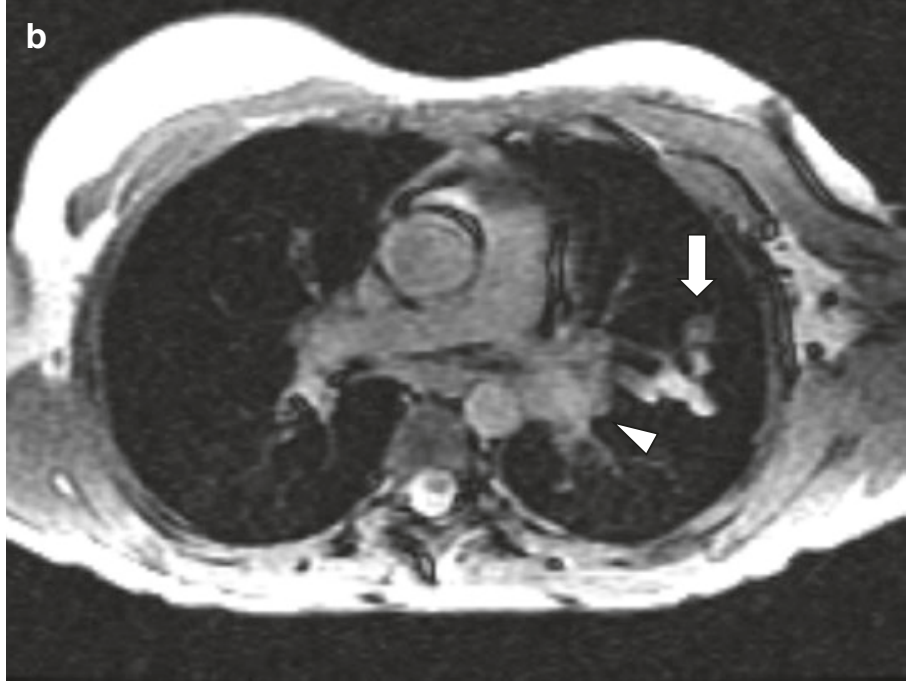

lobe, and left hilar adenopathy (arrowhead). (b) Axial non-enhanced SSFP T2/T1-weighted MR image shows left upper lobe nodule (arrow) and left hilar adenopathy (arrowhead) 


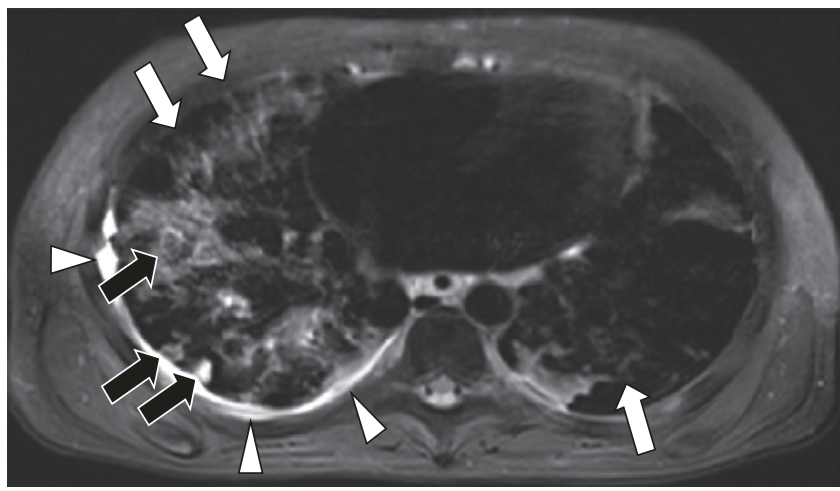

Fig. 1.21 Mycobacterium tuberculosis infection in 13-year-old boy with immunosuppression. Axial non-enhanced T2-weighted MR image shows multiple hyperintense and ground-glass pulmonary nodules (black arrows), bilateral interstitial thickening (white arrows), and small right pleural effusion (arrowheads)

have a solid center (which may cavitate) surrounded by a rim of ground-glass signal intensity, producing a "halo" sign [67]. These findings are most often described on chest radiograph and CT, but they can also be seen on MR imaging as described in a following section.

Mycobacterial Infection (Tuberculosis) In the developing world, tuberculosis (TB) continues to be a significant cause of community-acquired illness and, in the developed world, TB primarily affects patients who are immunocompromised or patients who emigrate from the developing world (Fig. 1.21) [68-70]. Although chest radiograph and CT are the most commonly used imaging modalities to assess TB infection, MR imaging may be considered in certain scenarios. For example, MR imaging may be utilized in immunocompromised pediatric patients receiving multiple imaging studies in order to mitigate exposure to ionizing radiation.

The most common primary mode of transmission for TB infection is through inhalation of infected droplets, and the initial infection is termed primary TB. In children, primary infection most often causes mild symptoms with no findings on imaging studies [71]. Less often, primary infection may cause more significant symptoms and be accompanied by mediastinal and hilar lymphadenopathy and pulmonary parenchymal opacity (see Fig. 1.21) [72, 73]. Lymphadenopathy is most often mild, but in a minority of cases, lymph nodes can become significantly enlarged and cause significant bronchial obstruction [74, 75]. Pleural effusion occurs in approximately $22 \%$ of children with primary TB infection (see Fig. 1.21) [76]. In pri- mary infection, MR imaging may be normal or demonstrate pulmonary consolidation, pulmonary nodules, pleural effusion, or lymphadenopathy (see Fig. 1.21) [77, 78].

Dormant infection may become active at a time after primary infection, referred to as reactivation TB. Symptoms typically include fever, night sweats, productive cough, and hemoptysis. Imaging findings in reactivation TB typically include upper lobe consolidation with cavitation [79]. MR imaging may demonstrate upper lobe consolidation as a region of increased signal on fluid-sensitive sequences and show central necrosis as a region of relatively lower signal intensity within the consolidation [78].

Hematogenous spread of TB infection can lead to innumerable small nodules scattered throughout the lungs, liver, and spleen, termed miliary infection [73]. Young children and immunocompromised pediatric patients are at higher risk for miliary disease. In miliary infection, MR imaging shows innumerable 1-3 mm nodules within the lungs, liver, and spleen.

Parasitic Infection (e.g., Hydatid Disease) Pulmonary hydatid disease is caused by infection with Echinococcus granulosus, a parasite whose definitive host is the dog or other canids and intermediate host is sheep, goats, pigs, cattle, horses, or camels. Children may become infected by ingesting the eggs of the parasite located within feces of infected canids. After ingestion, the eggs hatch in the child's gastrointestinal tract and larvae enter the bloodstream. By hematogenous spread, larvae can then form cysts throughout the body; the two most common locations are the liver and the lung. Although most hydatid infections occur during childhood, the hydatid infection is often indolent, and affected patients may not present until adulthood [80]. Pulmonary hydatid disease is rare in many regions of the world, but, in endemic regions, it is a common differential diagnosis for a cystic lung lesion [81]. Hydatid cysts are composed of three layers (pericyst, laminated layer, and germinal layer) with membranes between them [82].

Pulmonary hydatid disease may first be detected on chest radiograph as a single $(81 \%)$ or multiple $(19 \%)$ round densities ranging in size from 1 to $20 \mathrm{~cm}$ [83-85]. On $\mathrm{CT}$, these lesions demonstrate internal fluid density and a smooth wall that is higher density than fluid (Fig. 1.22). If cyst communicates with the airway an "air-crescent" sign may be seen and a "water lilly" sign may be seen when a collapsed endocyst floats within a cyst $[85,86]$. MR imaging may help differentiate pulmonary hydatid disease from other cystic lung lesions by showing characteristic hypoin- 

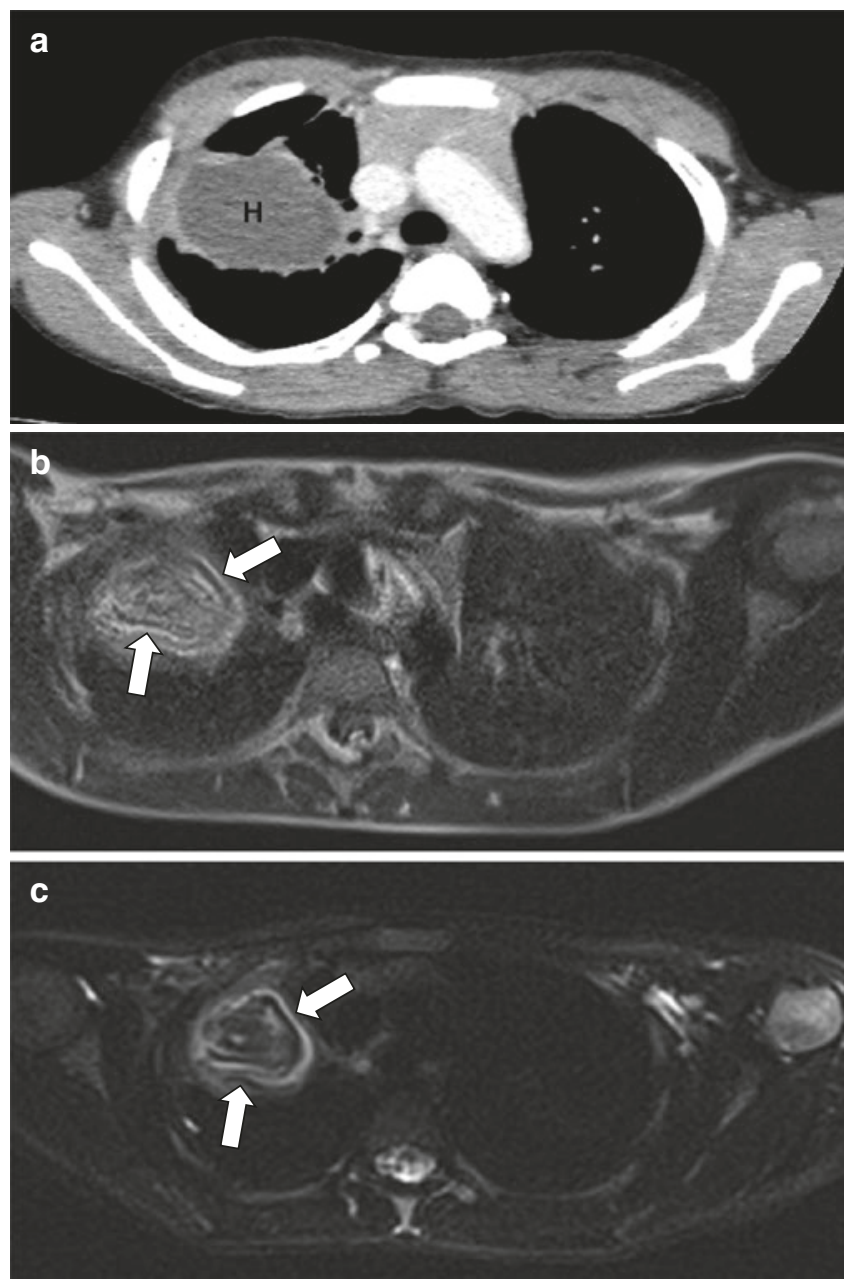

Fig. 1.22 Pulmonary hydatid disease in a 10-year-old boy who presented with chest pain and cough. (Courtesy of Kushaljit Singh Sodhi, MD, PhD, Department of Radiodiagnosis, Postgraduate Institute of Medical Education and Research, Chandigarh, India). (a) Axial enhanced soft tissue window setting CT image shows cystic lesion $(\mathrm{H})$ with peripheral enhancement in the right upper lobe. (b) Axial non-enhanced T2-HASTE-weighted MR image shows internal folded membranes (arrows) within the cystic lesion. (c) Axial non-enhanced T2-BLADE-weighted MR image shows internal folded membranes (arrows) within the cystic lesion

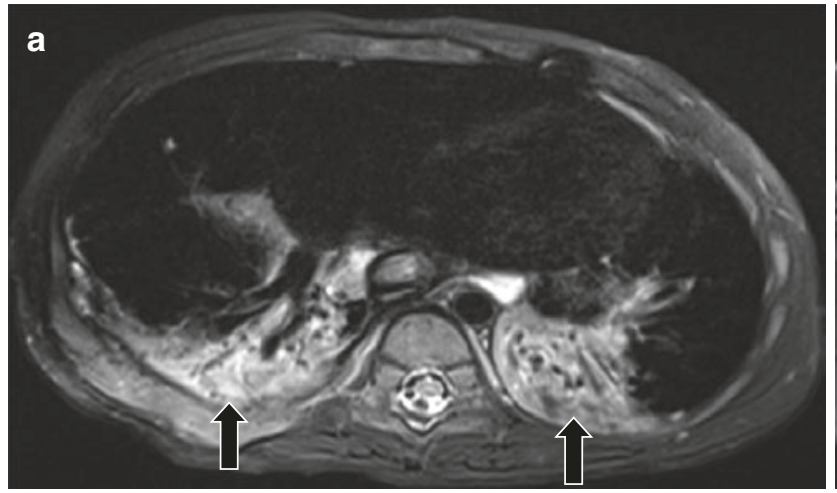

Fig. 1.23 Aspiration-related bilateral lower lobe consolidation in a 3 -year-old boy with esophageal atresia repair. (a) Axial non-enhanced T2-weighted fat-suppressed MR image shows bilateral lower lobe con- tense folded membrane within the cyst and a hypointense rim surrounding the cyst (see Fig. 1.22) [81]. Recent prospective study which compared MR and contrast-enhanced MDCT for evaluation of pediatric pulmonary hydatid disease showed that fast MR imaging without contrast material is comparable to contrast-enhanced MDCT for accurately diagnosing lung cysts in pediatric patients with pulmonary hydatid disease. However, added diagnostic value demonstrating internal membranes of cysts, which is specific to pulmonary hydatid disease, was provided by MR imaging in comparison to MDCT [87].

MR imaging Findings of Infectious Disorders of the Lung and Pleura Pulmonary infection may produce a number of different findings on MR imaging. The following section illustrates these MR imaging findings.

Lung Consolidation Pulmonary consolidation is common in bacterial pneumonia. On CT, pulmonary consolidation appears as opacified lung which obscures pulmonary vessels, often with air bronchograms [88]. On MR imaging, homogenous signal intensity fills the normally hypointense lung and obscures pulmonary vessels (Fig. 1.23 and see Fig. 1.15) [88]. On T2-weighted sequences, the signal within pulmonary consolidation is typically greater than the signal in skeletal muscle. On contrast-enhanced T1-weigthed images with fat suppression, the region of consolidation typically enhances homogenously, unless there is necrosis.

Ground-Glass Signal Pulmonary infection may lead to ground-glass abnormalities within the lungs. On CT, ground-glass opacities are defined as opacities which are denser than the air-filled lung, but not dense enough to obscure the pulmonary vasculature. On MR imaging, ground-glass signal is defined as hyperintense signal within the lungs that is more intense than the air-filled lung

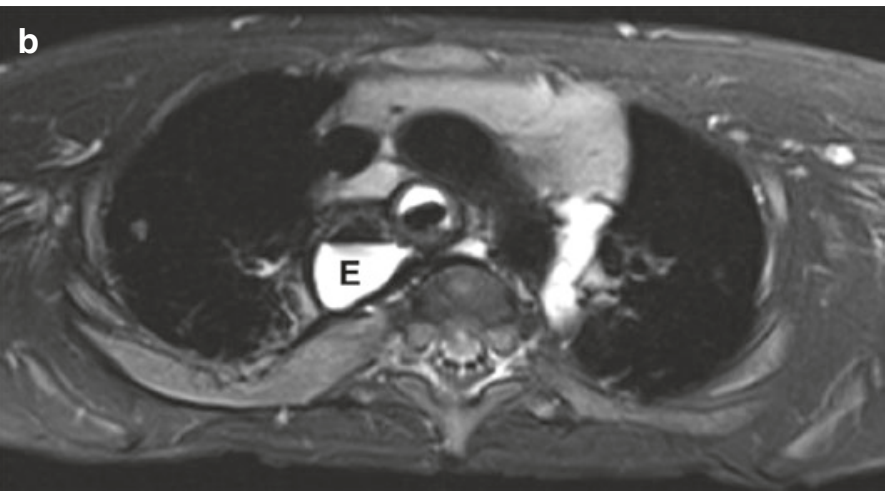

solidation (arrows). (b) Axial non-enhanced T2-weighted fatsuppressed MR image shows a dilated fluid-filled esophagus (E) 
but does not obscure the pulmonary vasculature (Fig. 1.24 and see Fig. 1.16) [88]. Pulmonary infection may lead to ground-glass signal within the lungs, or areas of mixed consolidation and ground-glass signal. Ground-glass signal can also be seen surrounding a central nodule, producing a "halo" sign seen in fungal and other infections [67].

Lung Abscess and Necrosis Pulmonary infection can progress from consolidation and ground-glass abnormalities to pulmonary necrosis and abscess if there is interruption of the blood supply to the lung. Pulmonary necrosis describes devitalized lung which loses its normal architecture and often contains irregularly shaped pockets of air and coalescing fluid. Pulmonary necrosis evolves into pulmonary abscess when a wall forms around a region of devitalized lung (Fig. 1.25) [65, 89, 90]. On MR imaging,

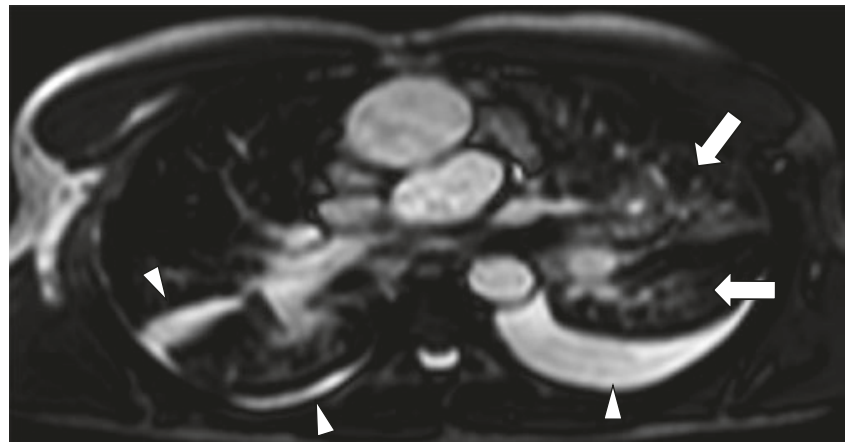

Fig. 1.24 Bronchopneumonia causing ground-glass signal abnormality in a 13-year-old boy who presented with fever and cough. Axial non-enhanced bright-blood T2-weighted MR image shows peribronchial ground-glass signal abnormality (arrows) in the left upper and left lower lobe and bilateral pleural effusions (arrowheads)

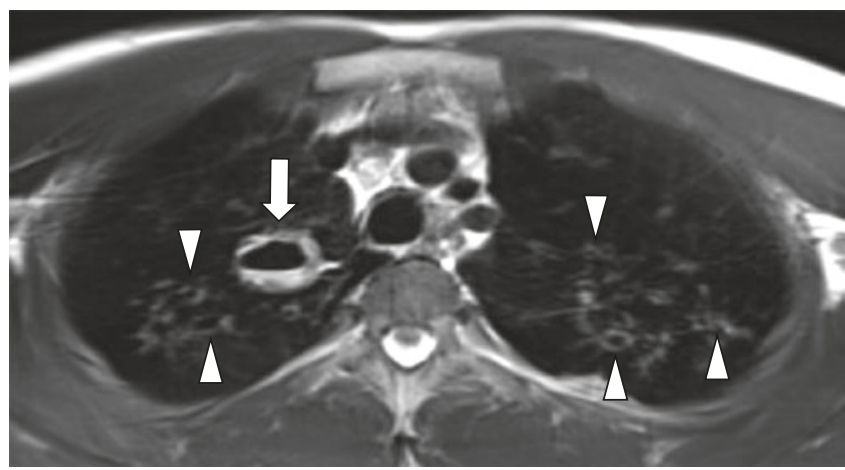

Fig. 1.25 Pulmonary abscess in a 17-year-old girl with cystic fibrosis, fever, and cough. Axial non-enhanced bright-blood MR image shows a cavity (arrow) containing an air-fluid level within the right upper lobe and bilateral bronchiectasis (arrowheads) with bronchial wall thickening pulmonary necrosis is defined as an area of lung consolidation without enhancement on contrast-enhanced images. On T2-weighted images, necrosis may be appreciated as a region of lower signal centered within a higher-signal region of consolidation. Like on chest radiograph and CT, irregularly shaped locules of air may be seen within a region of pulmonary necrosis, and an air-filled cavity or a cavity with an air-fluid level may be seen in pulmonary abscess (see Fig. 1.25) [91].

Internal Membrane (e.g., Hydatid Disease) Hydatid cysts are composed of three layers: the outermost pericyst, the middle laminated layer sometimes called the ectocyst, and the innermost germinal layer also known as the endocyst [82]. Each of these layers is separated by a membrane, and visualization of these membranes may aid in the diagnosis of pulmonary hydatid disease (see Fig. 1.22).

Pulmonary hydatid cysts appear as smooth-walled cystic masses, which contain fluid that is hyperintense on T2-weighted images and does not enhance on contrastenhanced images. MR imaging may be helpful for differentiating hydatid cysts from other cystic masses by demonstrating a characteristic hypointense rim surrounding the cyst and a folded hypointense membrane within the cyst (see Fig. 1.22) [81, 87].

Bronchiectasis Bronchiectasis may occur as a complication of pulmonary infection and is defined as irreversible dilation of a bronchus or bronchiole. Bronchiectasis may also occur in the setting of cystic fibrosis or ciliary dyskinesia [86, 92-96]. Bronchiectasis can be diagnosed on MR imaging when the diameter of a bronchus is greater than the diameter of the pulmonary artery adjacent to it [65]. Because bronchi are air-filled structures surrounded by a thin wall, CT is often better at depicting bronchiectasis than MR imaging. However, the bronchial walls are often thickened and inflamed in bronchiectasis, and these bronchial walls are often hyperintense and visible on T2-weighted MR images (see Fig. 1.25).

Pleural Effusion Simple pleural effusions may occur in cases of pulmonary infection. In these cases, infection may not spread to the pleural space, but the pleural effusion is reactive to the adjacent inflammatory process. In these cases, pleural fluid is homogenous and hyperintense on $\mathrm{T} 2$-weighted images and hypointense on $\mathrm{T} 1$-weighted images, and pleural membranes are thin without thickening or hyperenhancement on contrast-enhanced MR images (see Figs. 1.16 and 1.24) [97]. Thoracentesis and chest tube placement may be performed for symptom relief 
when simple effusions are large or to sample fluid in cases of suspected empyema.

Empyema When infection spreads from the lung into the pleural space, an empyema occurs. The appearance of an empyema differs from the appearance of a simple pleural effusion. In empyema, MR imaging may show heterogeneous signal within the pleural space on T2-weighted images due to septations or complex material (see Fig. 1.17) [91]. On contrast-enhanced images, the pleural membranes are typically thickened and hyperenhancing. Empyema may be treated with one of two strategies: antibiotics, chest tube placement, and infusion of fibrinolytics to the pleural space or video-assisted thoracoscopic surgery (VATS)assisted drainage [98, 99].

\section{Neoplastic Lung and Pleural Disorders}

Primary neoplasms of the lungs and pleura are rare and metastatic disease is much more common in the pediatric population [100, 101]. Most neoplasms of the lungs and pleura are first detected on chest radiographs and then further evaluated with CT. MR imaging may be utilized in select scenarios where radiation exposure is a concern or as a part of whole-body MR imaging [102]. The MR imaging appearance of pulmonary and pleural neoplasms is discussed in the following sections.

\section{Benign Primary Neoplasms of Lung and Pleura Benign} primary neoplasms of the lung and pleura are rare in children. Benign neoplasms that may occur in children include pulmonary hamartoma, pulmonary chondroma, respiratory papillomatosis, pulmonary sclerosing pneumocytoma, pulmonary inflammatory myofibroblastic tumor, and pleural fibrous pseudotumor [103]. Given the rarity of these entities, there is little in the medical literature describing the MR imaging appearance of many of these entities, though some have been described.

Pulmonary hamartomas are smooth or slightly lobulated solitary pulmonary nodules which may contain fat or calcification. On MR imaging, hamartomas demonstrate hyperintensity on T2-weighted images and early peripheral enhancement that becomes homogenous on delay-phase images (Fig. 1.26) [104]. Cleft-like structures separating small cystic spaces have been described within pulmonary hamartomas on T2-weighted and contrast-enhanced images $[104,105]$, and chemical shift MR imaging can aid in detection of fat within lesions [106].

Inflammatory myofibroblastic tumors are low-grade mesenchymal tumors that may present as solitary circum-

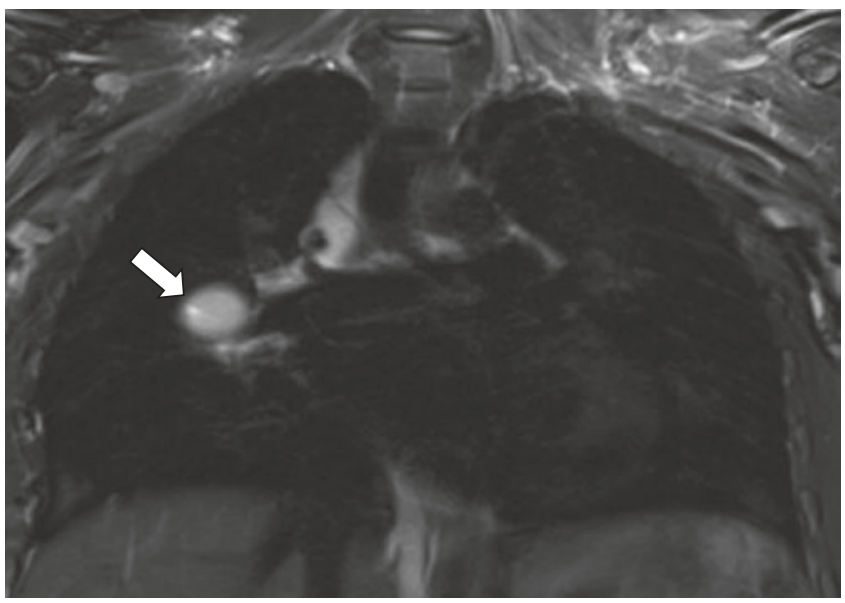

Fig. 1.26 Pulmonary hamartoma in a 13-year-old girl. Coronal nonenhanced T2-weighted fat-suppressed MR image shows a right perihilar hyperintense solitary pulmonary nodule (arrow) with a smooth margin

scribed pulmonary nodules or masses or can be infiltrative [107]. In the limited literature describing the MR imaging appearance, inflammatory myofibroblastic tumors may be heterogeneous on $\mathrm{T} 2$-weighted images with heterogeneous enhancement and necrosis on contrast-enhanced imaging (Fig. 1.27) [108].

Malignant Primary Neoplasms of Lung and Pleura Malignant primary neoplasms of the lung and pleura are rare in children. Entities include pleuropulmonary blastoma (PPB), pulmonary carcinoid tumor, bronchogenic carcinoma, mucoepidermoid tumor, and epithelioid hemangioendothelioma. As with the benign tumors, there is little in the medical literature describing the MR imaging appearance of many of these entities, although some have been described.

PPB is an aggressive embryonal tumor that arises from the lung or less often from the pleura. PPB is associated with a hereditary tumor predisposition syndrome which includes cystic nephroma, stromal sex-cord ovarian tumors, seminomas or dysgerminomas, intestinal polyps, thyroid hyperplasias, hamartomas, and medulloblastoma [109]. PBB and this hereditary tumor predisposition syndrome are associated with a mutation in the DICER1 gene [110]. There are three types of PPB: type I is purely cystic, type II is cystic and solid, and type III is completely solid. The median age at diagnosis for type I is 8 months, type II is 35 months, and type III is 41 months [111]. The MR imaging appearance depends on the type. In type III, masses are typically large and heterogeneous on T1- and T2-weighted images and often contain regions of necrosis which do not enhance on contrast-enhanced images (Fig. 1.28) [112]. 

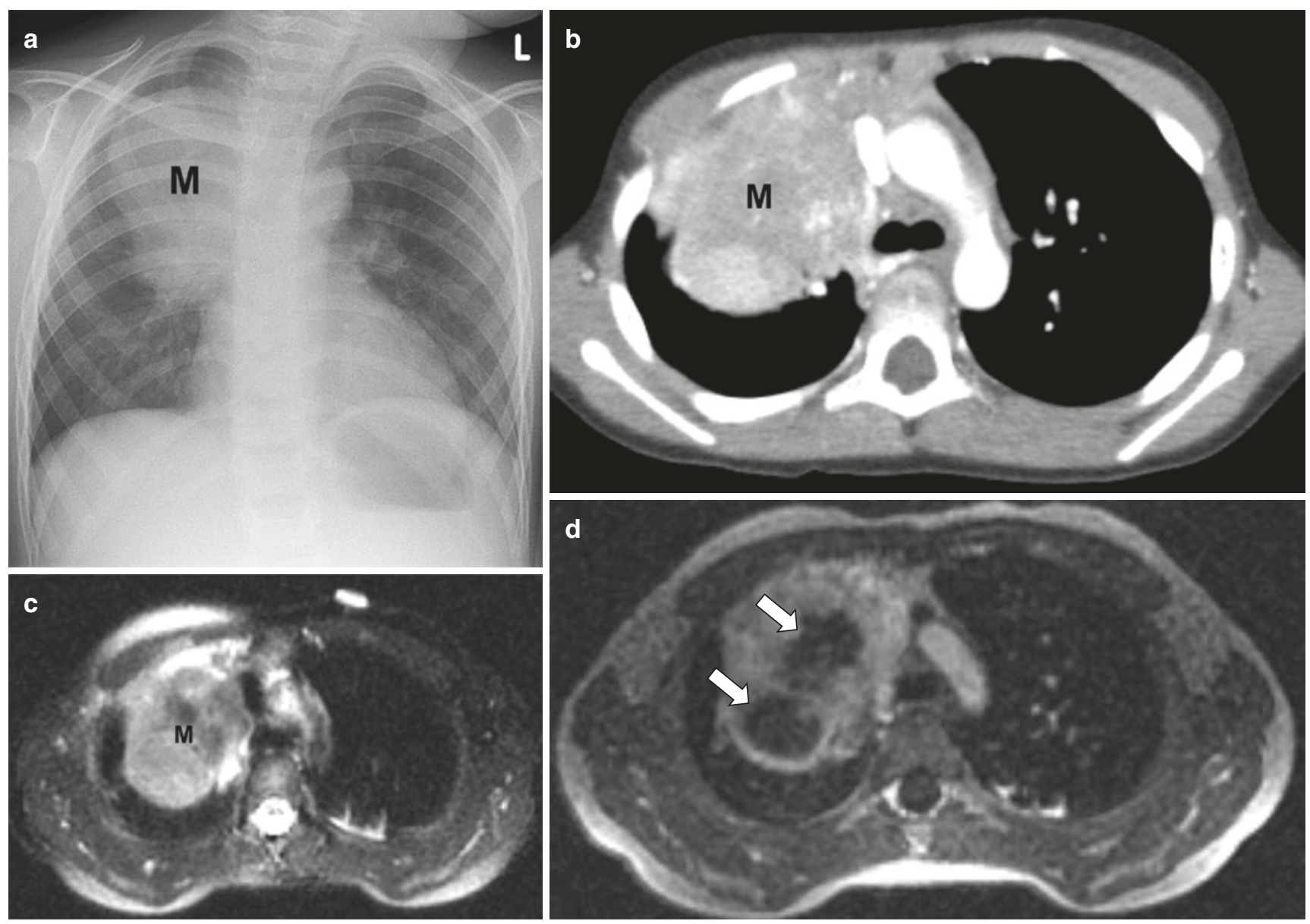

Fig. 1.27 Pulmonary inflammatory myofibroblastic tumor in a 5-year-old boy. (a) Frontal chest radiograph shows a large right upper lobe mass (M). (b) Axial enhanced soft tissue window setting CT image shows the right upper lobe mass (M) demonstrating heterogeneous enhancement. (c) Axial non-enhanced SSFSE T2-weighted MR image shows the right upper lobe mass (M) demonstrating heterogeneous signal intensity. (d) Axial enhanced T1-weighted fat-suppressed MR image shows regions of non-enhancement (arrows) within the mass, indicating necrosis

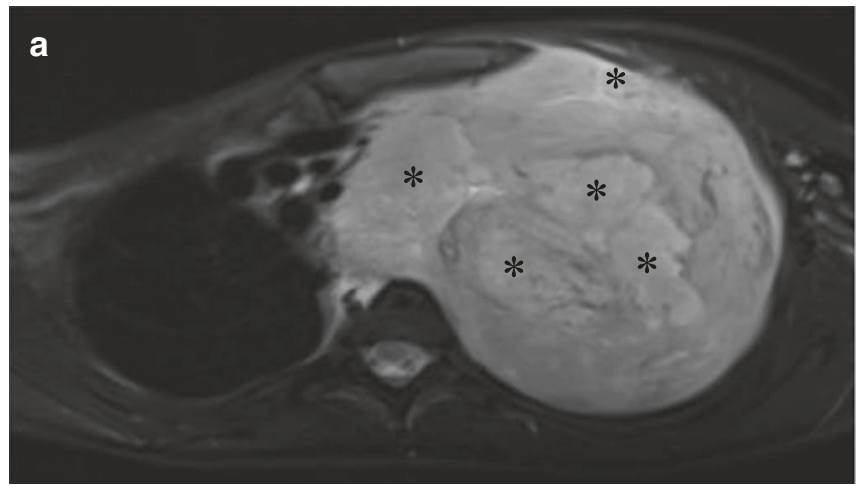

Fig. 1.28 Type III pleuropulmonary blastoma in a 5-year-old girl. (a) Axial non-enhanced T2-weighted fat-suppressed MR image shows a large heterogeneously hyperintense left upper lobe mass which exerts mass effect on the mediastinum. Regions of greater hyperintensity

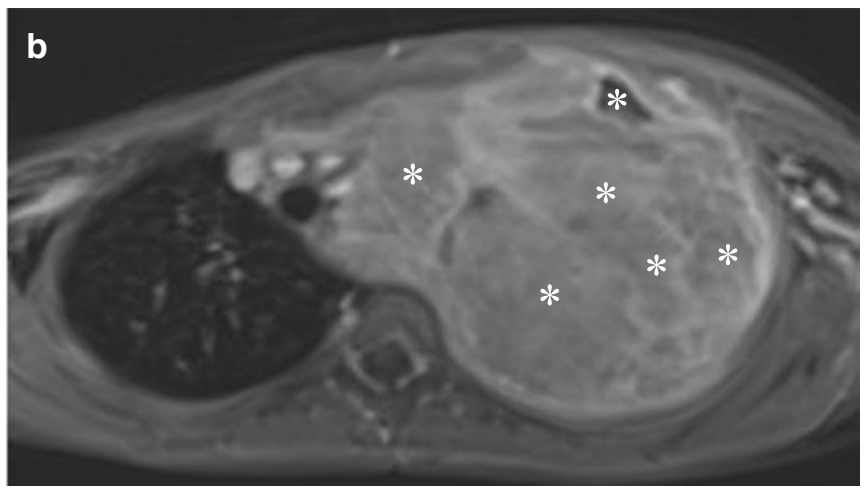

(asterisks) within the mass correspond to regions of necrosis. (b) Axial enhanced T1-weighted fat-suppressed MR image shows heterogenous enhancement within the mass with several non-enhancing regions (asterisks), indicating necrosis 

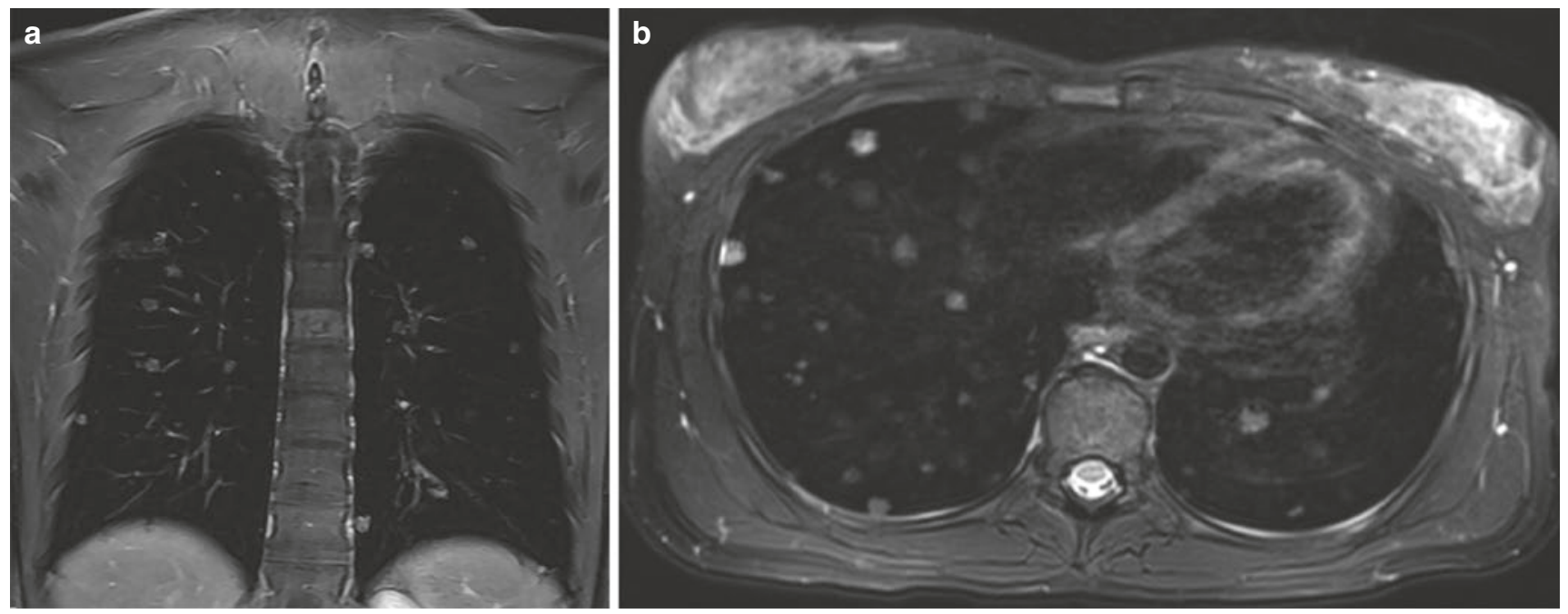

Fig. 1.29 Epithelioid hemangioendothelioma in a 16-year-old girl. (a) Coronal non-enhanced T2-weighted fat-suppressed MR image shows multiple bilateral hyperintense pulmonary nodules. (b) Axial non- enhanced T2-weighted fat-suppressed MR image shows multiple bilateral hyperintense pulmonary nodules
Epithelioid hemangioendothelioma is a rare vascular sarcoma that can occur at any age and any organ in the body including the lung and pleura [113-115]. Three patterns on imaging are described with thoracic epithelioid hemangioendothelioma: multiple pulmonary nodules, multiple pulmonary reticulonodular opacities, or diffuse infiltrative pleural thickening [116]. Although these findings have been described on CT, similar findings are seen on MR imaging (Fig. 1.29).

Metastatic Neoplasm of Lung and Pleura Metastatic disease is much more common than primary malignancy in the thorax in the pediatric population. In children, pulmonary metastatic disease is $\mathbf{1 1 . 6}$ times more common than primary pulmonary malignancy [101]. In children with a known primary malignancy, surveillance for thoracic metastases is most often achieved with CT given its excellent ability to detect pulmonary nodules with little motion artifact. MR imaging is able to reliably detect pulmonary metastases $\geq 5 \mathrm{~mm}[117,118]$, but early identification of small pulmonary metastasis $(<4 \mathrm{~mm})$ has significant implications for treatment and survival; therefore, CT is currently the preferred method for evaluation of pulmonary metastatic disease. MR imaging may be considered to monitor known pulmonary metastases during therapy in select scenarios or may be used as a part of whole-body screening in patients with hereditary cancer syndromes.

On MR imaging, metastatic pulmonary nodules typically appear isointense to skeletal muscle on T1-weighted images, slightly hyperintense to skeletal muscle on T2- weighted images and demonstrate variable enhancement on contrastenhanced images (Fig. 1.30). Because pulmonary nodules contain signal-producing protons, they are typically easily detectible on the background of hypointense aerated lung, although respiratory motion artifact can obscure small nodules. Pulmonary metastatic disease is most often characterized by multiple pulmonary nodules but can also disseminate within the lung via the lymphatic system, in a process called lymphangitic spread (Fig. 1.31).

Pleural effusions may also occur in metastatic disease. In cases of pulmonary metastasis with reactive pleural effusions, the pleural effusions typically contain simple fluid that is hypointense on T1-weighted images and hyperintense on T2-weighted images without associated enhancement. In cases of metastatic spread to the pleura, pleural effusions are accompanied by pleural nodularity, pleural enhancement, and pleural fluid may be complex and contain septations (see Fig. 1.30).

\section{Other Pulmonary and Pleural Conditions Which May Be Evaluated on MR imaging}

Pulmonary Edema Pulmonary edema is a condition where fluid accumulates with the pulmonary interstitium and alveoli. Pulmonary edema may be cardiogenic or non-cardiogenic. Cardiogenic pulmonary edema is most commonly due to depressed left ventricular function or obstructed pulmonary venous return. Non-cardiogenic edema may be due to fluid overload, as in cases of excessive intravenous fluid administration or renal failure, or due to increased pulmonary capillary permeability, as in cases of drug toxicity, acute respiratory distress syndrome (ARDS), and neurogenic edema.

MR imaging findings of pulmonary edema are best appreciated on T2-weighted sequences. The interlobular septa are normally not visible on MR imaging, but, in cases of intersti- 

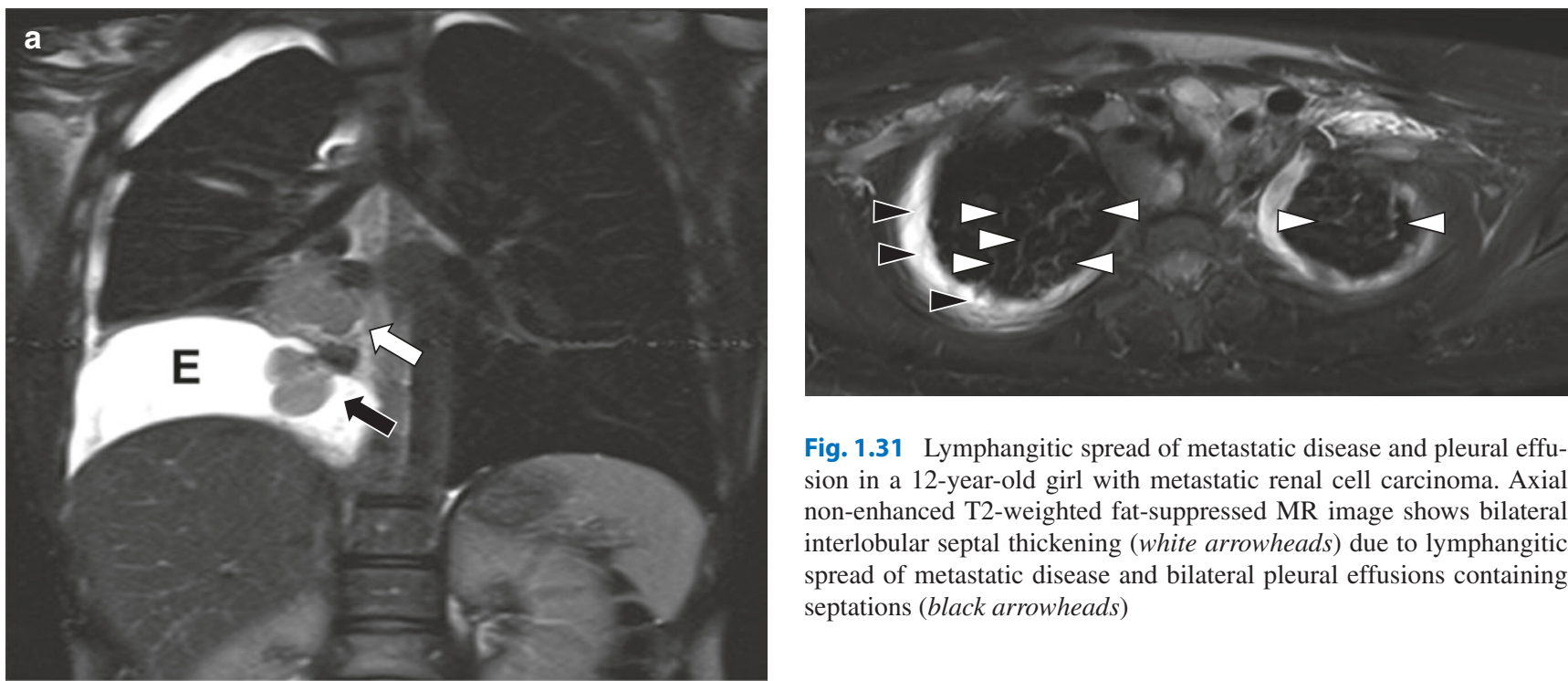

Fig. 1.31 Lymphangitic spread of metastatic disease and pleural effusion in a 12-year-old girl with metastatic renal cell carcinoma. Axial non-enhanced T2-weighted fat-suppressed MR image shows bilateral interlobular septal thickening (white arrowheads) due to lymphangitic spread of metastatic disease and bilateral pleural effusions containing septations (black arrowheads)
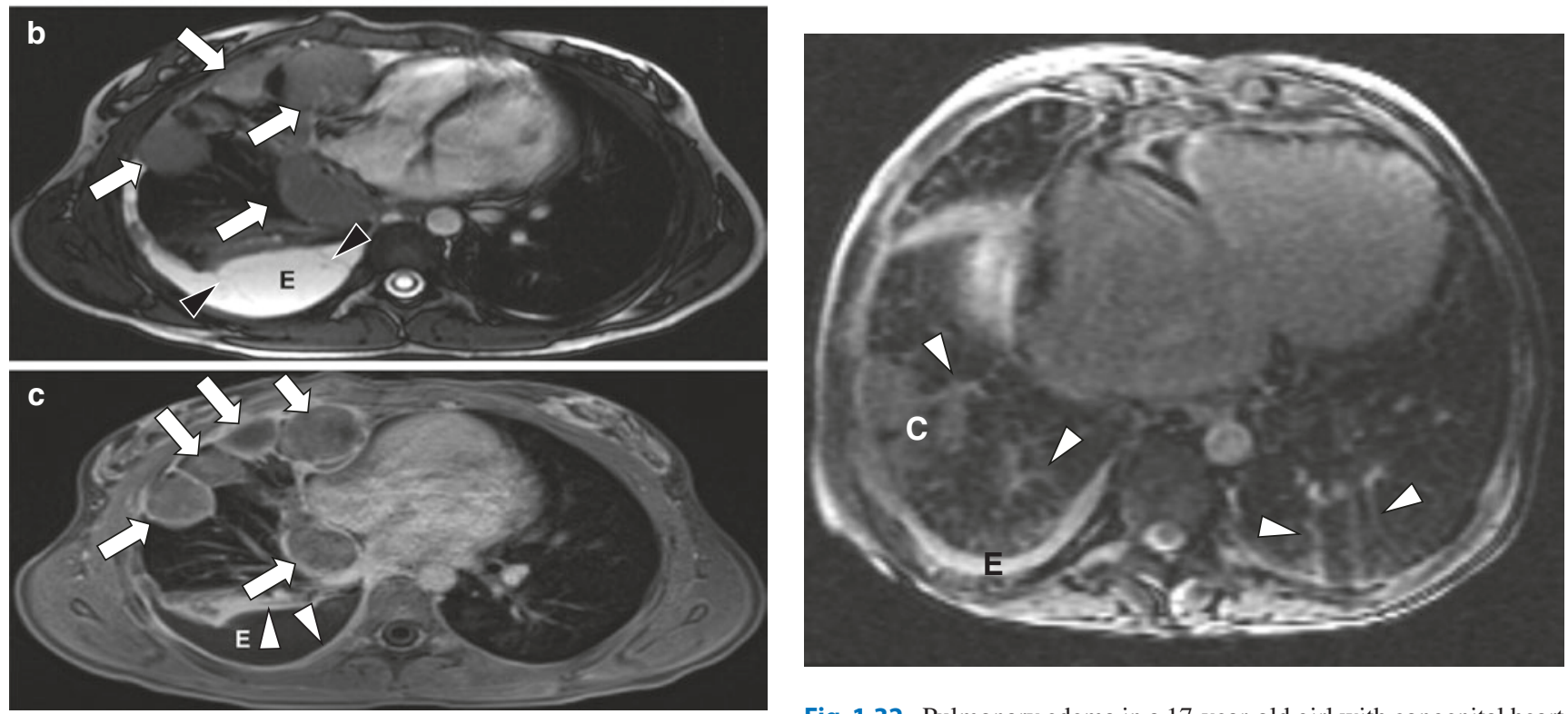

Fig. 1.30 Pulmonary and pleural metastases in a 14-year-old girl with synovial cell sarcoma of the left knee. (a) Coronal nonenhanced T2-weighted fat-suppressed MR image shows metastatic nodules in the right lung (white arrow) and pleura (black arrow) and pleural effusion (E). (b) Axial non-enhanced T2-weighted fat-suppressed MR image shows metastatic nodules in the right lung (white arrows), pleural effusion (E), and septations (black arrowheads) in the pleura. (c) Axial enhanced T1-weighted fat-suppressed MR image shows central hypoenhancement within metastatic nodules in the right lung (white arrows) and pleural effusion (E) with enhancement of the pleura (arrowheads)

tial pulmonary edema, the septa become visible and hyperintense on T2-weighted images (Fig. 1.32). When fluid fills the alveoli, ground-glass signal and consolidation may be seen (Fig. 1.33 and see Fig. 1.32). MR imaging may also show pleural effusion and cardiomegaly in cases of cardiogenic pulmonary edema.

Fig. 1.32 Pulmonary edema in a 17-year-old girl with congenital heart disease. Axial non-enhanced T2-weighted MR image shows interlobular septal thickening (arrowheads), small region of consolidation (C), and small right pleural effusion (E). Cardiomegaly is also seen

Pleural Effusion Pleural effusions may form when excess production or decreased absorption of pleural fluid leads to accumulation within the pleural space. The most common causes of pleural effusion are infection, congestive heart failure, and malignancy (see Figs. 1.16, 1.17, 1.24, 1.30, 1.31, and 1.32). Exudative pleural effusions are composed of simple clear fluid. On MR imaging, exudative pleural effusions appear as homogenous fluid that is hyperintense on T2-weighted images and hypointense on T1-weighted images. If causing symptoms, exudative pleural effusions can be treated with chest tube placement. Fibrinopurulent pleural effusions occur when infection spreads to the pleural space and cause empyema (see Fig. 1.17). Empyema is described in detail in an earlier section. 

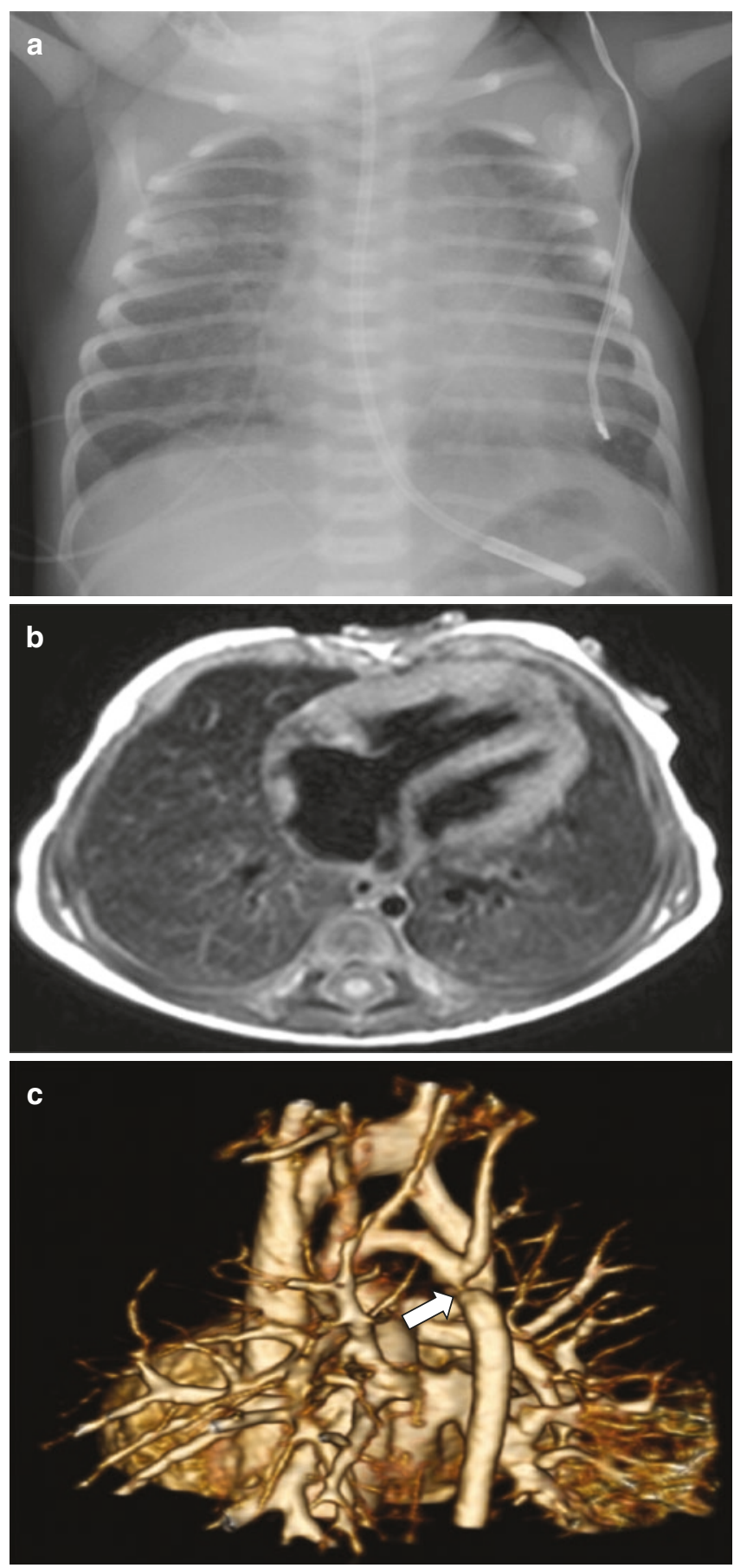

Fig. 1.33 Pulmonary edema in an 8-day-old girl with coarctation of aorta. (a) Frontal chest radiograph shows hazy bilateral pulmonary opacities due to pulmonary edema. (b) Axial non-enhanced T1-weighted MR image shows ground-glass signal intensity throughout both lungs. (c) Posterior projection from 3D reformatted MR image of the mediastinal vessels shows focal narrowing (arrow) of the aorta distal to the origin of the left subclavian artery
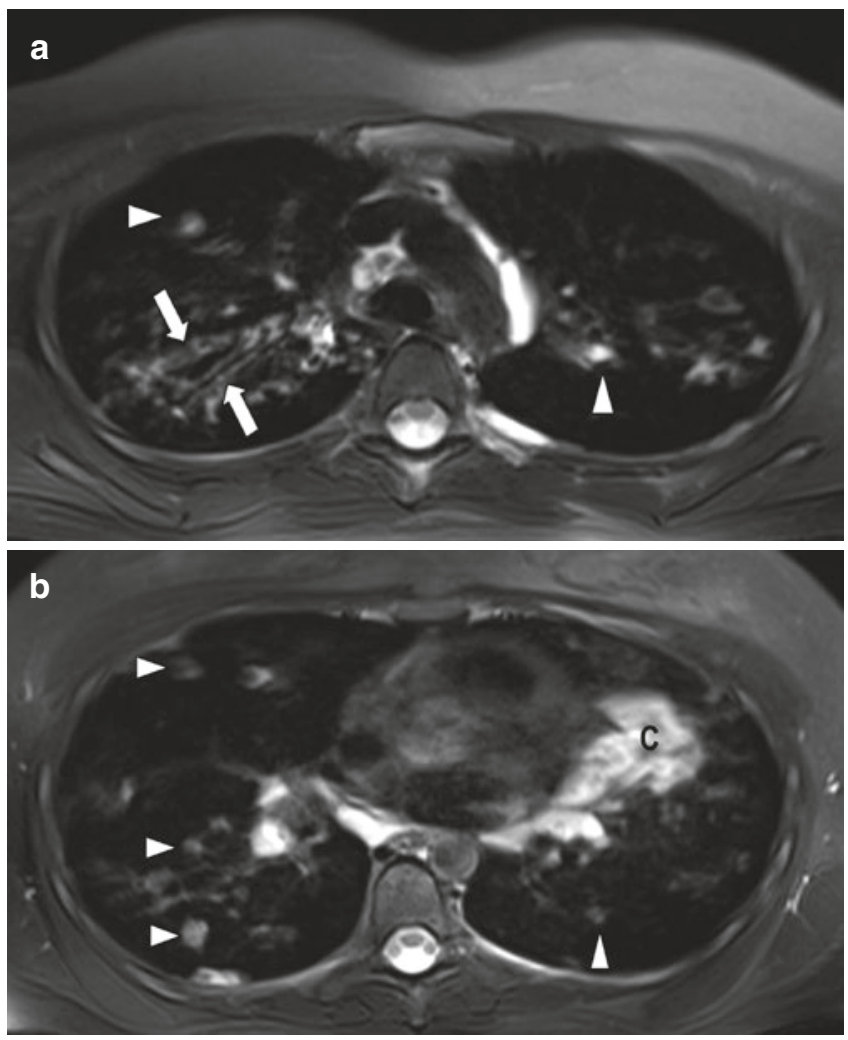

Fig. 1.34 Cystic fibrosis in a 17-year-old girl. (a) Axial non-enhanced T2-weighted fat-suppressed MR image shows bronchiectasis with bronchial wall thickening (white arrows) and hyperintense pulmonary nodules (white arrowheads). (b) Axial non-enhanced T2-weighted fatsuppressed MR image shows hyperintense pulmonary nodules (white arrowheads) and consolidation (C)

Cystic Fibrosis Cystic fibrosis (CF) is a multisystem genetic disease that primarily affects the lungs but also affects the gastrointestinal and genitourinary systems. CF is caused by mutations in the $\mathrm{CF}$ transmembrane regulator (CFTR) gene, leading to decreased transmembranous chloride transport causing secretions to be thick and viscous. In the lungs, CF causes mucus impaction, air trapping, bronchial wall thickening, and bronchiectasis [119-121].

Imaging is utilized in CF to evaluate superimposed infection but is also an important tool for monitoring disease progression. Although CT has historically filled this role, MR imaging has gained attention as an attractive alternative because repeated used of CT throughout the life of a patient with $\mathrm{CF}$ can lead to large cumulative radiation doses over time [122]. Many of the key imaging findings in CF produce increased signal on T2-weighted images, facilitating their 
detection on MR imaging (Fig. 1.34). For example, bronchiectasis with bronchial wall thickening, mucus plugs, and consolidation are detected on MR imaging with sensitivity comparable to CT [121, 123-125].

\section{Conclusion}

As MR imaging has become the primary imaging modality to assess many diseases in pediatric patients, its role in the evaluation of the lungs and pleura has lagged due to technical challenges unique to the thorax. However, in recent years, new advances in scanner, computing, and sequence technology have allowed many of these challenges to be overcome. Diagnostic imaging of the lungs and pleura is currently a feasible option for many pediatric patients in many medical centers. As practitioners become familiar with these new techniques and appreciate its potential role, MR imaging will likely be used more in the future when evaluating the spectrum of congenital and acquired pediatric pulmonary and pleural disorders.

\section{References}

1. Baez JC, Seethamraju RT, Mulkern R, Ciet P, Lee EY. Pediatric chest MR imaging: sedation, techniques, and extracardiac vessels. Magn Reson Imaging Clin N Am. 2015;23(2):321-35.

2. Ciet P, Tiddens HA, Wielopolski PA, Wild JM, Lee EY, Morana $\mathrm{G}$, et al. Magnetic resonance imaging in children: common problems and possible solutions for lung and airways imaging. Pediatr Radiol. 2015;45(13):1901-15.

3. Gibiino F, Sacolick L, Menini A, Landini L, Wiesinger F. Free-breathing, zero-TE MR lung imaging. MAGMA. 2015;28(3):207-15.

4. Dournes G, Grodzki D, Macey J, Girodet PO, Fayon M, Chateil JF, et al. Quiet submillimeter MR imaging of the lung is feasible with a PETRA sequence at 1.5 T. Radiology. 2015;276(1):258-65.

5. Ciet P, Serra G, Bertolo S, Spronk S, Ros M, Fraioli F, et al. Assessment of CF lung disease using motion corrected PROPELLER MRI: a comparison with CT. Eur Radiol. 2016;26(3):780-7.

6. Kumar S, Rai R, Stemmer A, Josan S, Holloway L, Vinod S, et al. Feasibility of free breathing lung MRI for radiotherapy using non-Cartesian k-space acquisition schemes. Br J Radiol. 2017;90(1080):20170037.

7. Ciet P, Bertolo S, Ros M, Andrinopoulou ER, Tavano V, Lucca $\mathrm{F}$, et al. Detection and monitoring of lung inflammation in cystic fibrosis during respiratory tract exacerbation using diffusion-weighted magnetic resonance imaging. Eur Respir J. 2017;50(1):1601437

8. Wielputz MO, Puderbach M, Kopp-Schneider A, Stahl M, Fritzsching E, Sommerburg O, et al. Magnetic resonance imaging detects changes in structure and perfusion, and response to therapy in early cystic fibrosis lung disease. Am J Respir Crit Care Med. 2014;189(8):956-65.

9. Dournes G, Menut F, Macey J, Fayon M, Chateil JF, Salel M, et al. Lung morphology assessment of cystic fibrosis using MRI with ultra-short echo time at submillimeter spatial resolution. Eur Radiol. 2016;26(11):3811-20.

10. Tiddens HA, Stick SM, Wild JM, Ciet P, Parker GJ, Koch A, et al. Respiratory tract exacerbations revisited: ventilation, inflammation, perfusion, and structure (VIPS) monitoring to redefine treatment. Pediatr Pulmonol. 2015;50(Suppl 40):S57-65.

11. Liszewski MC, Ciet P, Lee EY. MR imaging of lungs and airways in children: past and present. Magn Reson Imaging Clin N Am. 2019;27(2):201-25.

12. Shannon JM, Wikenheiser-Brokamp KA, Greenberg JM. Lung growth and development. In: Broaddus VC, editor. Murray \& Nadel's textbook of respiratory medicine. 6th ed. Philadelphia: Elsevier; 2016. p. 22-31, 19103-2899.

13. Gebb SA, Shannon JM. Tissue interactions mediate early events in pulmonary vasculogenesis. Dev Dyn. 2000;217(2):159-69.

14. Brown LM, Duck-Chong CG. Methods of evaluating fetal lung maturity. Crit Rev Clin Lab Sci. 1982;16(2):85-159.

15. Steinhorn RH. Pulmonary vascular development. In: Martin RJ, Fanaroff AA, Walsh MC, editors. Fanaroff and Martin's neonatalperinatal medicine: diseases of the fetus and infant. 10th ed. Philadelphia: Elsevier; 2015. p. 1198-209.

16. Bland RD. Lung epithelial ion transport and fluid movement during the perinatal period. Am J Phys. 1990;259(2 Pt 1):L30-7.

17. Jobe AH, Kamath-Rayne BD. Fetal lung development and surfactant. In: Creasy RK, Resnik R, Iams JD, Lockwood CJ, Moore TR, Greene MF, editors. Creasy and Resnik's maternal-fetal medicine: principles and practice. 7th ed. Philadelphia: Elsevier; 2014. p. $175-86$.

18. Ueda T, Ikegami M, Jobe AH. Developmental changes of sheep surfactant: in vivo function and in vitro subtype conversion. J Appl Physiol (1985). 1994;76(6):2701-6.

19. Rider ED, Jobe AH, Ikegami M, Sun B. Different ventilation strategies alter surfactant responses in preterm rabbits. J Appl Physiol (1985). 1992;73(5):2089-96.

20. Kallapur SG, Jobe AH. Lung development and maturation. In: Martin RJ, Fanaroff AA, Walsh MC, editors. Fanaroff and Martin's neonatal-perinatal medicine: diseases of the fetus and infant. 10th ed. Philadelphia: Elsevier; 2015.

21. Broaddus VC, Light RW. Pleural effusion. In: Broaddus VC, editor. Murray and Nadel's textbook of respiratory medicine. 6th ed. Philadelphia: Saunders; 2016. p. 1396-424.

22. Osborne DR, Effmann EL, Hedlund LW. Postnatal growth and size of the pulmonary acinus and secondary lobule in man. AJR Am J Roentgenol. 1983;140(3):449-54.

23. Webb WR. Thin-section CT of the secondary pulmonary lobule: anatomy and the image-the 2004 Fleischner lecture. Radiology. 2006;239(2):322-38.

24. Itoh H, Murata K, Konishi J, Nishimura K, Kitaichi M, Izumi T. Diffuse lung disease: pathologic basis for the high-resolution computed tomography findings. J Thorac Imaging. 1993;8(3):176-88.

25. Albertine K. Anatomy of the lungs. In: Broaddus VC, editor. Murray $\&$ Nadel's textbook of respiratory medicine. 6th ed. Philadelphia: Elsevier; 2016. p. 3-21.

26. Yildiz A, Golpinar F, Calikoglu M, Duce MN, Ozer C, Apaydin FD. HRCT evaluation of the accessory fissures of the lung. Eur J Radiol. 2004;49(3):245-9.

27. Ariyurek OM, Gulsun M, Demirkazik FB. Accessory fissures of the lung: evaluation by high-resolution computed tomography. Eur Radiol. 2001;11(12):2449-53.

28. Alamo L, Vial Y, Gengler C, Meuli R. Imaging findings of bronchial atresia in fetuses, neonates and infants. Pediatr Radiol. 2016;46(3):383-90.

29. Ko SF, Lee TY, Kao CL, Ng SH, Wan YL, Lin JW, et al. Bronchial atresia associated with epibronchial right pulmonary artery and aberrant right middle lobe artery. Br J Radiol. 1998;71(842):217-20. 
30. Naidich DP, Rumancik WM, Ettenger NA, Feiner HD, HernanzSchulman M, Spatz EM, et al. Congenital anomalies of the lungs in adults: MR diagnosis. AJR Am J Roentgenol. 1988;151(1):13-9.

31. Liszewski MC, Hersman FW, Altes TA, Ohno Y, Ciet P, Warfield SK, et al. Magnetic resonance imaging of pediatric lung parenchyma, airways, vasculature, ventilation, and perfusion: state of the art. Radiol Clin North Am. 2013;51(4):555-82.

32. Peranteau WH, Merchant AM, Hedrick HL, Liechty KW, Howell LJ, Flake AW, et al. Prenatal course and postnatal management of peripheral bronchial atresia: association with congenital cystic adenomatoid malformation of the lung. Fetal Diagn Ther. 2008;24(3):190-6.

33. Kunisaki SM, Fauza DO, Nemes LP, Barnewolt CE, Estroff JA, Kozakewich HP, et al. Bronchial atresia: the hidden pathology within a spectrum of prenatally diagnosed lung masses. J Pediatr Surg. 2006;41(1):61-5; discussion -5

34. Berrocal T, Madrid C, Novo S, Gutierrez J, Arjonilla A, GomezLeon N. Congenital anomalies of the tracheobronchial tree, lung, and mediastinum: embryology, radiology, and pathology. Radiographics. 2004;24(1):e17.

35. McAdams HP, Kirejczyk WM, Rosado-de-Christenson ML, Matsumoto S. Bronchogenic cyst: imaging features with clinical and histopathologic correlation. Radiology. 2000;217(2):441-6.

36. Alamo L, Reinberg O, Vial Y, Gudinchet F, Meuli R. Comparison of foetal US and MRI in the characterisation of congenital lung anomalies. Eur J Radiol. 2013;82(12):e860-6.

37. Rios LT, Araujo Junior E, Nardozza LM, Moron AF, Martins Mda G. Prenatal diagnosis and postnatal findings of bronchogenic cyst. Case Rep Pulmonol. 2013;2013:483864.

38. Pacharn P, Kline-Fath B, Calvo-Garcia M, Linam LE, Rubio EI, Salisbury S, et al. Congenital lung lesions: prenatal MRI and postnatal findings. Pediatr Radiol. 2013;43(9):1136-43.

39. Lee EY, Dorkin H, Vargas SO. Congenital pulmonary malformations in pediatric patients: review and update on etiology, classification, and imaging findings. Radiol Clin N Am. 2011;49(5):921-48.

40. Epelman M, Daltro P, Soto G, Ferrari CM, Lee EY. Congenital lung anomalies. In: Coley BD, editor. Caffey's pediatric diagnostic imaging. 12th ed. Philadelphia: Elsevier; 2013. p. 550-66.

41. Lee EY, Boiselle PM, Cleveland RH. Multidetector CT evaluation of congenital lung anomalies. Radiology. 2008;247(3):632-48.

42. Holder PD, Langston C. Intralobar pulmonary sequestration (a nonentity?). Pediatr Pulmonol. 1986;2(3):147-53.

43. Laurin S, Hagerstrand I. Intralobar bronchopulmonary sequestration in the newborn--a congenital malformation. Pediatr Radiol. 1999;29(3):174-8.

44. Riedlinger WF, Vargas SO, Jennings RW, Estroff JA, Barnewolt $\mathrm{CE}$, Lillehei $\mathrm{CW}$, et al. Bronchial atresia is common to extralobar sequestration, intralobar sequestration, congenital cystic adenomatoid malformation, and lobar emphysema. Pediatr Dev Pathol. 2006;9(5):361-73.

45. Langston C. New concepts in the pathology of congenital lung malformations. Semin Pediatr Surg. 2003;12(1):17-37.

46. Stocker JT, Madewell JE, Drake RM. Congenital cystic adenomatoid malformation of the lung. Classification and morphologic spectrum. Hum Pathol. 1977;8(2):155-71.

47. Stocker J. The respiratory tract. In: Stocker JT, LP D, editors. Pediatric pathology. 2nd ed. Philadelphia: Lippincott, Williams \& Wilkins; 2001. p. 466-73.

48. Alamo L, Gudinchet F, Reinberg O, Vial Y, Francini K, Osterheld MC, et al. Prenatal diagnosis of congenital lung malformations. Pediatr Radiol. 2012;42(3):273-83.

49. Epelman M, Kreiger PA, Servaes S, Victoria T, Hellinger JC. Current imaging of prenatally diagnosed congenital lung lesions. Semin Ultrasound CT MR. 2010;31(2):141-57.

50. MacSweeney F, Papagiannopoulos K, Goldstraw P, Sheppard MN, Corrin B, Nicholson AG. An assessment of the expanded clas- sification of congenital cystic adenomatoid malformations and their relationship to malignant transformation. Am J Surg Pathol. 2003;27(8):1139-46.

51. d'Agostino S, Bonoldi E, Dante S, Meli S, Cappellari F, Musi L. Embryonal rhabdomyosarcoma of the lung arising in cystic adenomatoid malformation: case report and review of the literature. J Pediatr Surg. 1997;32(9):1381-3.

52. Domizio P, Liesner RJ, Dicks-Mireaux C, Risdon RA. Malignant mesenchymoma associated with a congenital lung cyst in a child: case report and review of the literature. Pediatr Pathol. 1990;10(5):785-97.

53. Ozcan C, Celik A, Ural Z, Veral A, Kandiloglu G, Balik E. Primary pulmonary rhabdomyosarcoma arising within cystic adenomatoid malformation: a case report and review of the literature. J Pediatr Surg. 2001;36(7):1062-5.

54. Federici S, Domenichelli V, Tani G, Sciutti R, Burnelli R, Zanetti G, et al. Pleuropulmonary blastoma in congenital cystic adenomatoid malformation: report of a case. Eur J Pediatr Surg. 2001;11(3):196-9.

55. Burge D, Wheeler R. Increasing incidence of detection of congenital lung lesions. Pediatr Pulmonol. 2010;45(1):103; author reply: 4

56. Pryce DM. Lower accessory pulmonary artery with intralobar sequestration of lung; a report of seven cases. J Pathol Bacteriol. 1946;58(3):457-67.

57. Cannie M, Jani J, De Keyzer F, Van Kerkhove F, Meersschaert J, Lewi L, et al. Magnetic resonance imaging of the fetal lung: a pictorial essay. Eur Radiol. 2008;18(7):1364-74.

58. Eber E. Antenatal diagnosis of congenital thoracic malformations: early surgery, late surgery, or no surgery? Semin Respir Crit Care Med. 2007;28(3):355-66.

59. Laje P, Liechty KW. Postnatal management and outcome of prenatally diagnosed lung lesions. Prenat Diagn. 2008;28(7):612-8.

60. Rudan I, Tomaskovic L, Boschi-Pinto C, Campbell H. Global estimate of the incidence of clinical pneumonia among children under five years of age. Bull World Health Organ. 2004;82(12):895-903.

61. Jokinen C, Heiskanen L, Juvonen H, Kallinen S, Karkola K, Korppi $\mathrm{M}$, et al. Incidence of community-acquired pneumonia in the population of four municipalities in eastern Finland. Am J Epidemiol. 1993;137(9):977-88.

62. Daltro P, Santos EN, Gasparetto TD, Ucar ME, Marchiori E. Pulmonary infections. Pediatr Radiol. 2011;41(Suppl 1):S69-82.

63. Kim YW, Donnelly LF. Round pneumonia: imaging findings in a large series of children. Pediatr Radiol. 2007;37(12):1235-40.

64. Restrepo R, Palani R, Matapathi UM, Wu YY. Imaging of round pneumonia and mimics in children. Pediatr Radiol. 2010;40(12):1931-40.

65. Eslamy HK, Newman B. Pneumonia in normal and immunocompromised children: an overview and update. Radiol Clin N Am. 2011;49(5):895-920.

66. George R, Andronikou S, Theron S, du Plessis J, Hayes M, Goussard P, et al. Pulmonary infections in HIV-positive children. Pediatr Radiol. 2009;39(6):545-54.

67. Buckingham SJ, Hansell DM. Aspergillus in the lung: diverse and coincident forms. Eur Radiol. 2003;13(8):1786-800.

68. Alami NN, Yuen CM, Miramontes R, Pratt R, Price SF, Navin TR. Trends in tuberculosis - United States, 2013. MMWR Morb Mortal Wkly Rep. 2014;63(11):229-33.

69. Lobato MN, Hopewell PC. Mycobacterium tuberculosis infection after travel to or contact with visitors from countries with a high prevalence of tuberculosis. Am J Respir Crit Care Med. 1998;158(6):1871-5.

70. de Almeida CPB, Ziegelmann PK, Couban R, Wang L, Busse JW, Silva DR. Predictors of in-hospital mortality among patients with pulmonary tuberculosis: a systematic review and meta-analysis. Sci Rep. 2018;8(1):7230.

71. Marais BJ, Gie RP, Schaaf HS, Hesseling AC, Obihara CC, Starke $\mathrm{JJ}$, et al. The natural history of childhood intra-thoracic tuberculo- 
sis: a critical review of literature from the pre-chemotherapy era. In J Tuberc Lung Dis. 2004;8(4):392-402.

72. Leung AN, Muller NL, Pineda PR, FitzGerald JM. Primary tuberculosis in childhood: radiographic manifestations. Radiology. 1992;182(1):87-91.

73. Starke JR. Mycobacterium tuberculosis. In: Long SS, Pickering LK, Prober CG, editors. Principles and practice of pediatric infectious diseases. 4th ed. Philadelphia: Elsevier; 2012. p. 771-86.

74. Goussard P, Gie RP, Janson JT, le Roux P, Kling S, Andronikou S, et al. Decompression of enlarged mediastinal lymph nodes due to mycobacterium tuberculosis causing severe airway obstruction in children. Ann Thorac Surg. 2015;99(4):1157-63.

75. Goussard P, Gie R. Airway involvement in pulmonary tuberculosis. Paediatr Respir Rev. 2007;8(2):118-23.

76. Merino JM, Carpintero I, Alvarez T, Rodrigo J, Sanchez J, Coello JM. Tuberculous pleural effusion in children. Chest. 1999;115(1):26-30.

77. Rizzi EB, Schinina V, Cristofaro M, Goletti D, Palmieri F, Bevilacqua $\mathrm{N}$, et al. Detection of pulmonary tuberculosis: comparing MR imaging with HRCT. BMC Infect Dis. 2011; 11:243.

78. Peprah KO, Andronikou S, Goussard P. Characteristic magnetic resonance imaging low T2 signal intensity of necrotic lung parenchyma in children with pulmonary tuberculosis. J Thorac Imaging. 2012;27(3):171-4

79. Griffith-Richards SB, Goussard P, Andronikou S, Gie RP, Przybojewski SJ, Strachan M, et al. Cavitating pulmonary tuberculosis in children: correlating radiology with pathogenesis. Pediatr Radiol. 2007;37(8):798-804; quiz 48-9

80. Moro PL, Schantz PM. Echinococcus species (agents of cystic, alveolar, and polycystic echinococcosis). In: Long SS, Pickering LK, Prober CG, editors. Principles and practice of pediatric infectious diseases. 4th ed; 2012. p. 1356-62.

81. Tandur R, Irodi A, Chacko BR, Vimala LR, Christopher DJ, Gnanamuthu BR. Magnetic resonance imaging as an adjunct to computed tomography in the diagnosis of pulmonary hydatid cysts. Indian J Radiol Imaging. 2018;28(3):342-9.

82. Garg MK, Sharma M, Gulati A, Gorsi U, Aggarwal AN, Agarwal $\mathrm{R}$, et al. Imaging in pulmonary hydatid cysts. World $\mathrm{J}$ Radiol. 2016;8(6):581-7.

83. Sarkar M, Pathania R, Jhobta A, Thakur BR, Chopra R. Cystic pulmonary hydatidosis. Lung India. 2016;33(2):179-91.

84. Sadrizadeh A, Haghi SZ, Masuom SH, Bagheri R, Dalouee $\mathrm{MN}$. Evaluation of the effect of pulmonary hydatid cyst location on the surgical technique approaches. Lung India. 2014;31(4):361-5.

85. Turgut AT, Altinok T, Topcu S, Kosar U. Local complications of hydatid disease involving thoracic cavity: imaging findings. Eur J Radiol. 2009;70(1):49-56.

86. Westra SJ, Adler B, Yikilmaz A, Lee EY. Pulmonary infection. In: Coley BD, editor. Caffey's pediatric diagnostic imaging. 12th ed. Philadelphia: Elsevier; 2013. p. 567-81.

87. Sodhi KS, Bhatia A, Samujh R, Mathew JL, Lee EY. Prospective comparison of MRI and contrast-enhanced MDCT for evaluation of pediatric pulmonary hydatid disease: added diagnostic value of MRI. AJR Am J Roentgenol. 2019:1-6.

88. Attenberger UI, Morelli JN, Henzler T, Buchheidt D, Fink C, Schoenberg SO, et al. 3 Tesla proton MRI for the diagnosis of pneumonia/lung infiltrates in neutropenic patients with acute myeloid leukemia: initial results in comparison to HRCT. Eur J Radiol. 2014;83(1):e61-6.

89. Donnelly LF, Klosterman LA. Pneumonia in children: decreased parenchymal contrast enhancement-CT sign of intense illness and impending cavitary necrosis. Radiology. 1997;205(3): 817-20.

90. Donnelly LF. Practical issues concerning imaging of pulmonary infection in children. J Thorac Imaging. 2001;16(4):238-50.
91. Peltola V, Ruuskanen O, Svedstrom E. Magnetic resonance imaging of lung infections in children. Pediatr Radiol. 2008;38(11):1225-31.

92. Osborne D, White P. Radiology of epidemic adenovirus 21 infection of the lower respiratory tract in infants and young children. AJR Am J Roentgenol. 1979;133(3):397-400.

93. Brady MT, Marcon MJ. Pseudomonas and related genera. In: Cherry JD, Harrison GJ, Kaplan SL, Steinbach WJ, Hotez PJ, editors. Feigin and Cherry's textbook of pediatric infectious diseases. 7th ed. Philadelphia: Elsevier; 2014. p. 1582-605.

94. Chu HQ, Li B, Zhao L, Huang DD, Zhang ZM, Xu JF, et al. Chest imaging comparison between non-tuberculous and tuberculosis mycobacteria in sputum acid fast bacilli smear-positive patients. Eur Rev Med Pharmacol Sci. 2015;19(13):2429-39.

95. Maffessanti M, Candusso M, Brizzi F, Piovesana F. Cystic fibrosis in children: HRCT findings and distribution of disease. J Thorac Imaging. 1996;11(1):27-38.

96. Kennedy MP, Noone PG, Leigh MW, Zariwala MA, Minnix SL, Knowles MR, et al. High-resolution CT of patients with primary ciliary dyskinesia. AJR Am J Roentgenol. 2007;188(5):1232-8.

97. Gorkem SB, Coskun A, Yikilmaz A, Zurakowski D, Mulkern RV, Lee EY. Evaluation of pediatric thoracic disorders: comparison of unenhanced fast-imaging-sequence 1.5-T MRI and contrastenhanced MDCT. AJR Am J Roentgenol. 2013;200(6):1352-7.

98. Aziz A, Healey JM, Qureshi F, Kane TD, Kurland G, Green M, et al. Comparative analysis of chest tube thoracostomy and videoassisted thoracoscopic surgery in empyema and parapneumonic effusion associated with pneumonia in children. Surg Infect. 2008;9(3):317-23.

99. Kelly MM, Coller RJ, Kohler JE, Zhao Q, Sklansky DJ, Shadman $\mathrm{KA}$, et al. Trends in hospital treatment of empyema in children in the united states. J Pediatr. 2018;202:245-51.e1.

100. Tischer W, Reddemann H, Herzog P, Gdanietz K, Witt J, Wurnig $\mathrm{P}$, et al. Experience in surgical treatment of pulmonary and bronchial tumours in childhood. Prog Pediatr Surg. 1987;21:118-35.

101. Dishop MK, Kuruvilla S. Primary and metastatic lung tumors in the pediatric population: a review and 25-year experience at a large children's hospital. Arch Pathol Lab Med. 2008;132(7):1079-103.

102. Bueno MT, Martinez-Rios C, la Puente Gregorio A, Ahyad RA, Villani A, Druker $\mathrm{H}$, et al. Pediatric imaging in DICER1 syndrome. Pediatr Radiol. 2017;47(10):1292-301.

103. Erasmus JJ, McAdams HP, Patz EF Jr, Murray JG, Pinkard NB. Calcifying fibrous pseudotumor of pleura: radiologic features in three cases. J Comput Assist Tomogr. 1996;20(5):763-5.

104. Alexopoulou E, Economopoulos N, Priftis KN, Tsigka A, Kelekis NL. MR imaging findings of an atypical pulmonary hamartoma in a 12-year-old child. Pediatr Radiol. 2008;38(10):1134-7.

105. Park KY, Kim SJ, Noh TW, Cho SH, Lee DY, Paik HC, et al. Diagnostic efficacy and characteristic feature of MRI in pulmonary hamartoma: comparison with CT, specimen MRI, and pathology. J Comput Assist Tomogr. 2008;32(6):919-25.

106. Hochhegger B, Marchiori E, dos Reis DQ, Souza AS Jr, Souza LS, Brum T, et al. Chemical-shift MRI of pulmonary hamartomas: initial experience using a modified technique to assess nodule fat. AJR Am J Roentgenol. 2012;199(3):W331-4.

107. Surabhi VR, Chua S, Patel RP, Takahashi N, Lalwani N, Prasad SR. Inflammatory myofibroblastic tumors: current update. Radiol Clin North Am. 2016;54(3):553-63.

108. Naime S, Bandarkar A, Nino G, Perez G. Pulmonary inflammatory myofibroblastic tumour misdiagnosed as a round pneumonia. BMJ Case Rep. 2018;2018:bcr-2017-224091.

109. Priest JR, Williams GM, Hill DA, Dehner LP, Jaffe A. Pulmonary cysts in early childhood and the risk of malignancy. Pediatr Pulmonol. 2009;44(1):14-30. 
110. Hill DA, Ivanovich J, Priest JR, Gurnett CA, Dehner LP, Desruisseau D, et al. DICER1 mutations in familial pleuropulmonary blastoma. Science. 2009;325(5943):965.

111. Messinger YH, Stewart DR, Priest JR, Williams GM, Harris AK, Schultz KA, et al. Pleuropulmonary blastoma: a report on 350 central pathology-confirmed pleuropulmonary blastoma cases by the International Pleuropulmonary Blastoma Registry. Cancer. 2015;121(2):276-85.

112. Papaioannou G, Sebire NJ, McHugh K. Imaging of the unusual pediatric ‘blastomas'. Cancer Imaging. 2009;9:1-11.

113. Hettmer S, Andrieux G, Hochrein J, Kurz P, Rossler J, Lassmann $\mathrm{S}$, et al. Epithelioid hemangioendotheliomas of the liver and lung in children and adolescents. Pediatr Blood Cancer. 2017;64(12)

114. Siraj S, Akhter S, Rizvi N. Primary pleural epitheliod hemangioendothelioma with lung involvement. J Coll Physicians Surg Pak. 2017;27(9):S120-s1.

115. Mucientes P, Gomez-Arellano L, Rao N. Malignant pleuropulmonary epithelioid hemangioendothelioma - unusual presentation of an aggressive angiogenic neoplasm. Pathol Res Pract. 2014;210(9):613-8.

116. Kim EY, Kim TS, Han J, Choi JY, Kwon OJ, Kim J. Thoracic epithelioid hemangioendothelioma: imaging and pathologic features. Acta Radiol. 2011;52(2):161-6.

117. Hirsch W, Sorge I, Krohmer S, Weber D, Meier K, Till H. MRI of the lungs in children. Eur J Radiol. 2008;68(2):278-88.

118. Gorkem S, Coskun A, Yikilmaz A, Zurakowski D, Mulkern R, Lee E. Evaluation of pediatric thoracic disorders: comparison of unen- hanced fast-imaging sequence 1.5T MRI with contrast-enhanced MDCT. AJR Am J Roentgenol. 2013;200(6):1352-7.

119. Mott LS, Park J, Murray CP, Gangell CL, de Klerk NH, Robinson PJ, et al. Progression of early structural lung disease in young children with cystic fibrosis assessed using CT. Thorax. 2012;67(6):509-16.

120. Sly PD, Gangell CL, Chen L, Ware RS, Ranganathan S, Mott LS, et al. Risk factors for bronchiectasis in children with cystic fibrosis. N Engl J Med. 2013;368(21):1963-70.

121. Wielputz MO, Mall MA. Imaging modalities in cystic fibrosis: emerging role of MRI. Curr Opin Pulm Med. 2015;21(6): 609-16.

122. Wielputz MO, Eichinger M, Puderbach M. Magnetic resonance imaging of cystic fibrosis lung disease. J Thorac Imaging. 2013;28(3):151-9.

123. Puderbach M, Eichinger M, Gahr J, Ley S, Tuengerthal S, Schmahl A, et al. Proton MRI appearance of cystic fibrosis: comparison to CT. Eur Radiol. 2007;17(3):716-24.

124. Puderbach M, Eichinger M, Haeselbarth J, Ley S, KoppSchneider A, Tuengerthal S, et al. Assessment of morphological MRI for pulmonary changes in cystic fibrosis (CF) patients: comparison to thin-section CT and chest x-ray. Investig Radiol. 2007;42(10):715-25.

125. Murphy KP, Maher MM, O'Connor OJ. Imaging of cystic fibrosis and pediatric bronchiectasis. AJR Am J Roentgenol. 2016;206(3):448-54. 